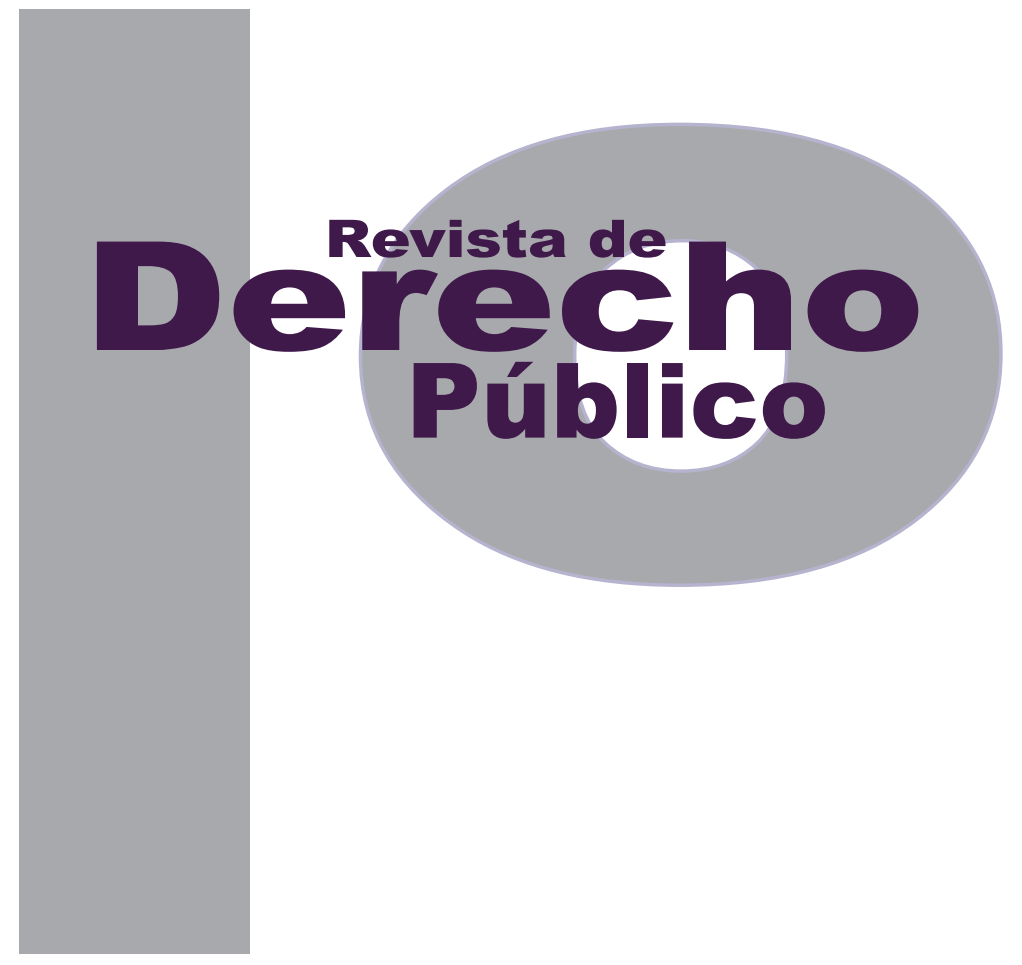

\title{
LA AUTONOMÍA DEL ARBITRAJE DOMÉSTICO DESDE LA PERSPECTIVA CONSTITUCIONAL EN COLOMBIA Y PUNTUALES ANÁLISIS DE DERECHO COMPARADO LATINOAMERICANO
}

\author{
Pablo Rey Vallejo \\ Artículo de reflexión \\ DOI: http://dx.doi.org/10.15425/redepub.34.2015.17 \\ Universidad de los Andes \\ Facultad de Derecho \\ Revista de Derecho Público N. ${ }^{\circ} 34$ \\ Enero - Junio de 2015. ISSN 1909-7778
}




\section{La autonomía del arbitraje doméstico desde la perspectiva constitucional en Colombia y puntuales análisis de derecho comparado latinoamericano}

\section{Resumen}

El presente artículo aborda el tema de la constitucionalización del arbitraje en Colombia y la evolución que esta materia ha seguido desde la perspectiva del Texto Fundamental. De igual manera, se destacan algunas experiencias latinoamericanas para ilustrar el tratamiento que otros ordenamientos constitucionales dan a este mecanismo de solución de controversias y el impacto que dichas fórmulas tienen en la práctica arbitral.

Palabras clave: arbitraje doméstico, constitucionalización del derecho privado, acción de tutela en el arbitraje, arbitraje como derecho fundamental.

\section{Colombian constitutional perspective on domestic arbitration autonomy and particular views from Latin American comparative law}

\section{Abstract}

This article addresses the issue of the constitutionalization of arbitration in Colombia and the evolution of this matter over the years. Similarly, highlights some Latin American experiences to illustrate the treatment that other constitutional provisions give to arbitration and the impact of these formulas.

Keywords: domestic arbitration, constitutionalization of private law, special constitutional action in arbitration, arbitration as fundamental right.

\section{A autonomia da arbitragem doméstica desde a perspectiva constitucional na Colômbia e análises pontuais de direito comparado latino-americano}

\section{Resumo}

O presente artigo aborda o tema da constitucionalização da arbitragem na Colômbia e a evolução que esta matéria tem seguido desde a perspectiva do Texto Fundamental. De igual maneira, são destacadas algumas experiências latinoamericanas para ilustrar o tratamento que outros ordenamentos constitucionais dão a este mecanismo de solução de controvérsias e o impacto que ditas fórmulas têm na prática arbitral.

Palavras-chave: arbitragem doméstica, constitucionalização do direito privado, ação de tutela na arbitragem, arbitragem como direito fundamental. 


\title{
La autonomía del arbitraje doméstico desde la perspectiva constitucional en Colombia y puntuales análisis de derecho comparado latinoamericano*
}

\author{
Pablo Rey Vallejo**
}

\begin{abstract}
SUMARIO
Introducción - I. TRATAMIENTO CONSTITUCIONAL DEL ARBITRAJE - A. El caso colombiano - 1. Antecedentes a la Carta de 1991 - 2. La Constitución de 1991 - a). El arbitraje como mecanismo de "descongestión de despachos judiciales" b). El carácter jurisdiccional del arbitraje y el árbitro como juez - c). El arbitraje como proceso y el laudo como sentencia judicial - d). La acción de tutela contra las decisiones arbitrales - B. Algunas experiencias del derecho constitucional latinoamericano - 1. El arbitraje como derecho fundamental - a). La asimilación “directa” en el Texto Constitucional b). La asimilación "indirecta” del arbitraje como derecho fundamental - II. DIVERSAS POSTURAS ACERCA DEL PROCESO DE CONSTITUCIONALIZACIÓN DEL ARBITRAJE - A. Posturas que favorecen la constitucionalización del arbitraje - B. Posturas que desincentivan la constitucionalización del arbitraje - III. CONCLUSIÓN - Referencias.
\end{abstract}

Cómo citar este artículo: Rey Vallejo, P. (Junio, 2015). La autonomía del arbitraje doméstico desde la perspectiva constitucional en Colombia y puntuales análisis de derecho comparado latinoamericano. Revista de Derecho Público, 34. Universidad de los Andes (Colombia).

Forma parte integral del documento de tesis que elabora el autor en el programa de Doctorado en Ciencias Jurídicas de la Universidad Javeriana.

** Abogado de la Universidad de los Andes. LL.M. -International Business Law- de la Universidad de Londres - London School of Economics and Political Science. 
Introducción

La constitucionalización del derecho privado es un fenómeno cuyo estudio ha cobrado un auge significativo en los últimos años. Acertadamente, Mourre (2007) lo caracterizó como uno en el cual se revelan evoluciones y contradicciones profundas entre autonomía privada e interés general, que nos invita a una reflexión transversal sobre la tensión entre valores colectivos y libertad individual. Entonces, esta forma de "sacralización" de esta rama del derecho integra los principios de la autonomía contractual a un cuerpo de normas imperativas que sirven de base para la organización misma del Estado.

Si bien la temática de fondo del presente trabajo no involucra ahondar en los orígenes de la constitucionalización del derecho privado, es menester resaltar que dicho proceso hunde sus raíces, entre otras, en razones de índole política y cultural. Señala Mourre (2007), desde la primera perspectiva, que el debilitamiento del poder público en favor de la creciente competencia de los mercados ha generado, en alguna medida, mayores preocupaciones por el impacto social que esa dinámica lleva implícita y, por consiguiente, una tendencia hacia el regreso de ciertas formas de nacionalismo, especialmente en el ámbito latinoamericano. La segunda arista se caracteriza por un mayor grado de relativismo, contrapuesto a algunos absolutismos generadores de grandes injusticias del siglo pasado, y de un especial cuidado por los derechos individuales, particularmente protegidos en las actuales cartas políticas de la región.
Especial consideración merece igualmente lo relativo a la constitucionalización del derecho procesal, dada la cercanía que con esta área del derecho tiene el arbitraje en algunas jurisdicciones. Bajo esta perspectiva, puede entenderse que la constitucionalización en el ámbito procesal conlleva la constitucionalización indirecta de una rama específica del derecho privado como el arbitraje. En efecto, si en un ordenamiento jurídico se reconocen el acceso a la administración de justicia y el debido proceso como derechos constitucionales inalienables, y a la vez se le atribuye a los tribunales de arbitramento el desempeño de funciones jurisdiccionales y a los laudos el carácter de sentencia judicial, surge en ese caso una inescindible relación entre el derecho derivado de la Carta Fundamental y este mecanismo de solución de controversias.

Ahora bien, para algunos autores esta vinculación entre el arbitraje y el Texto Constitucional guarda una estrecha relación con el hecho de que el arbitraje se "inscribe en el tema de la justicia" y más específicamente en el derecho de acceso a la justicia y a los órganos del sistema nacional que la instrumentan (Hernández-Bretón, 2007). Sin embargo, resulta discutible en muchas jurisdicciones que el arbitraje forme parte de dicha estructura, por lo que la respuesta a esta problemática puede variar de una normativa a otra según las consagraciones constitucionales, legales y reglamentarias que reconocen este medio alternativo.

Entonces, el arbitraje y el derecho de acceso a los órganos de administración de justicia no necesariamente deben confundirse, ya que si bien 
esta relación es clara en algunos sistemas no necesariamente puede afirmarse que en todo caso el arbitraje haga parte de estos o que se trate de la misma cosa, si bien ambos participan de valores en común (Victoria-Andreu, 2007).

El anterior escenario nos plantea la necesidad de abordar el tema de la constitucionalización del arbitraje desde una perspectiva comparada, que permita reflexionar acerca de las diferentes variables existentes en el tratamiento de esta materia y el impacto que dichas fórmulas tienen en la práctica arbitral. Se brindará especial atención a algunos sistemas jurídicos latinoamericanos en los que, al igual que en el caso colombiano, el desarrollo de la figura se debe en gran parte al impulso determinante de instituciones de carácter público y privado que promovieron y financiaron proyectos para la promulgación de normativas nacionales y la creación de centros de arbitraje. Es el caso, entre otros, del Fondo Multilateral de Inversiones del Banco Interamericano de Desarrollo, que desde los años ochenta y noventa del siglo pasado adelantó programas en los que, con la participación de expertos internacionales en la materia, se actualizaron un número importante de legislaciones latinoamericanas que contribuyeron al crecimiento de instituciones promotoras de este mecanismo alternativo.

Adicionalmente, es de anotar que en el entorno latinoamericano se encuentra abundante literatura relacionada con la constitucionalización del arbitraje, dado que dicho fenómeno está presente en un sinnúmero de ordenamientos, tanto por la inclusión de la figura por vía directa en el Texto Constitucional o por el reconocimiento de esta como de categoría constitucional, como por cuenta de la jurisprudencia (González de Cossío, 2005).

Señala Conejero Roos (2009), que la relación entre las constituciones políticas de los países latinoamericanos y el arbitraje es de larga data y encuentra su origen tanto en normativas anteriores a la época de las independencias como en textos constitucionales posteriores a ellas. En efecto, estos vínculos entre Constitución y arbitraje, en los que se hace patente la tensión Estado-orden público-autonomía privada, sumados a una serie de consideraciones históricas, han derivado en críticas a la utilización del arbitraje en algunos países de la región. Este fenómeno es aún perceptible en algunos Estados en los que el arbitraje es objeto de críticas que permiten desviar la atención sobre debates que son, en su esencia, de mayor relevancia en el campo de lo político, lo económico o lo social.

No obstante lo anterior, esta tendencia no es del todo generalizada. En efecto, Cremades y Cairns (2002) resaltan que a pesar de que es conocida la reputación "antiarbitraje" que han tenido históricamente algunos países de América Latina, la adopción de leyes modernas y la ratificación de convenciones internacionales sobre la materia han sido esenciales para superarla y han ayudado a que algunos de estos países alcancen los estándares impuestos por la economía global.

Sentadas las anteriores consideraciones, se propone abordar en este texto la temática de la 
constitucionalización del arbitraje en los siguientes términos: en primera instancia lo relativo al tratamiento constitucional del arbitraje (parte I), sus antecedentes y el desarrollo actual a la luz de la Carta Política colombiana (sección A), así como las experiencias de algunos otros países de América Latina en los que las fórmulas constitucionales consagratorias del mecanismo difieren de las posturas adoptadas por el constituyente colombiano (sección B); en segunda medida, se analizan algunas de las posiciones más relevantes que los doctrinantes nacionales e internacionales han expuesto en relación con el fenómeno de la constitucionalización (parte II), haciendo especial énfasis en las visiones en favor (sección A) y en contra de este (sección B).

\section{TRATAMIENTO CONSTITUCIONAL DEL ARBITRAJE}

Como se analizará más adelante, la tentación por constitucionalizar el arbitraje no constituye el único vehículo para reconocer esta figura como un instrumento válido dentro del ordenamiento jurídico. Por el contrario, algunos aseguran que su incorporación en el Texto Superior no es en absoluto necesaria para que su reconocimiento en el plano legal o reglamentario derive en su plena eficacia y operatividad. El cotejo de las normas de inferior rango con una Carta Política en la que su reconocimiento brilla por su ausencia no puede derivar en una inexorable sanción por inexequibilidad, dado que sus raíces se entrelazan con principios de honda jerarquía constitucional como los de la libertad contractual y económica.
La decisión libre y soberana del constituyente por vincular la figura del arbitraje al Texto Fundamental ha revestido diversas formas a lo largo de los últimos años. Evidentemente, no todos los textos constitucionales integran de manera unívoca este sistema de solución de conflictos, por el contrario, existen casos en los que el constituyente optó por incorporar la figura al sistema orgánico jurisdiccional, mientras que, en otros casos, la visión se encaminó a asimilarla a un derecho de categoría fundamental.

A primera vista, las consecuencias prácticas derivadas de la opción "constitucionalizadora" son diversas: en el primer caso, la asimilación del arbitraje a un proceso judicial deriva en la aplicación al trámite arbitral de una serie de normas de carácter procesal, así como su ineludible vinculación con principios como el del libre acceso a la administración de justicia o la protección del debido proceso. Por otro lado, la consagración del arbitraje como derecho fundamental, deriva en que su protección puede darse en un plano de respeto a la libertad contractual sin que necesariamente puedan invocarse figuras o procedimientos propios de la jurisdicción para favorecer o entorpecer el acceso a la vía arbitral. No obstante, como se verá más adelante, estas asociaciones no son absolutas en todos los casos.

\section{A. El caso colombiano}

Si bien la práctica arbitral ha crecido exponencialmente en el país a lo largo de los últimos años, resulta difícil afirmar que dicho crecimiento haya tenido origen en la evolución del esce- 
nario constitucional y no por cuenta de los múltiples y fructíferos esfuerzos que han realizado los operadores arbitrales nacionales, especialmente los centros de arbitraje.

El panorama constitucional del arbitraje en Colombia no ha sido del todo homogéneo en el curso de nuestra historia reciente. Para los efectos del presente trabajo, se identifican dos grandes etapas de dicha evolución, así: una primera instancia, bajo la Carta Política de 1886, en la que el arbitraje no se encontraba incorporado en el Texto Fundamental, y un segundo período que inició con la promulgación de la Constitución de 1991 en el que, afortunada o desafortunadamente, como se evalúa más adelante, la figura se incorporó en su texto.

\section{Antecedentes a la Carta de 1991}

Aunque el arbitraje no surgió en Colombia a partir de la Constitución Política de 1991, su consagración en la norma superior constituyó una novedad frente a la Carta Fundamental de 1886, en la que esta figura no se encontraba incorporada. No obstante lo anterior, para la Corte Suprema de Justicia, juez constitucional de la época, su constitucionalidad estaba plenamente sustentada (Cámara de Comercio de Bogotá, 2008).

La Corte, en decisión de 29 de mayo de 1969 analizó el artículo 58 superior que definía la justicia como un servicio público a cargo de la $\mathrm{Na}$ ción. En varios apartados de este fallo, se reafirmó la visión contractualista del arbitraje, fundada en la decisión autónoma de los particulares de otorgar a los árbitros la facultad de resolver su conflicto con fuerza de sentencia. No obstante, el máximo órgano constitucional señaló que la función jurisdiccional podían ejercerla no solo las Cortes y tribunales existentes en la época sino también aquellos otros órganos de similar categoría creados por la ley. En este sentido, las leyes 105 de 1931 y 02 de 1938, consagratorias del arbitraje, se constituían en un desarrollo de dicho presupuesto.

En este orden de ideas, a la luz del sistema jurídico imperante en el marco de la anterior Constitución, es posible afirmar que este instrumento de solución de diferencias no contaba con unas características significativamente distintas a aquellas que se le atribuyen el día de hoy. En efecto, por cuenta de la referencia contenida en el Texto Superior y la jurisprudencia analizada, era permitido el ejercicio de función jurisdiccional por aquellos estamentos judiciales que la ley expresamente autorizara.

Para la Corte, dentro de este último grupo se encontraban los tribunales de arbitramento, que si bien contaban con unas características especiales, se ubicaban en un plano similar al de los tribunales y juzgados que formaban parte de la jurisdicción permanente, dado que su viabilidad estaba sustentada en la autorización constitucional para crear "tribunales y juzgados" (cs), Plena, 29 may. 1969, L. Sarmiento).

Para algunos autores, la citada jurisprudencia significó un importante avance en cuanto a la visión contractualista de la figura, no obstante haberse reafirmado la ubicación del arbitraje 
en el plano de los órganos judiciales creados por la ley. Para este sector de la doctrina, si se hubiese reiterado esta línea jurisprudencial, la práctica del arbitraje doméstico en Colombia sería mucho más adecuada. De esta misma manera, otros sistemas de arbitraje de América Latina que replicaron el modelo colombiano se hubieran beneficiado (cs,, Plena, 29 may. 1969, L. Sarmiento).

En efecto, la visión contractualista del arbitraje, expresada en la sentencia arriba citada, sufrió una serie de mutaciones dentro del mismo escenario constitucional, cuando la Corte Suprema de Justicia, en sentencia de marzo 21 de 1991, se desprendió de los parámetros y lineamientos trazados en aquel pronunciamiento de finales de los años sesenta. En esta última providencia, la Corte hizo un particular énfasis en la visión jurisdiccional del arbitraje y asimiló la función de los tribunales de arbitramento al ejercicio de derechos políticos, exclusivos de los ciudadanos colombianos (cs, Plena, 21 mar. 1991, P. Escobar).

Este pronunciamiento le dio otra perspectiva a la visión primigenia que tenía el máximo órgano constitucional de la época sobre el arbitraje, en la cual se entendía que los tribunales de arbitramento tenían plena validez, por cuenta del mandato constitucional, de permitir a la ley crear tribunales y juzgados, pero que sus funciones estaban principalmente soportadas en la plena autonomía de la voluntad de las partes. Bajo esta premisa, infortunadamente superada en esta última decisión, se dio al traste con la visión de que dichos tribunales no administraban justicia "en el nombre de la República de Colombia" sino por cuenta de aquella manifestación libre, típicamente privada, a la cual el Estado soberano le atribuía una fuerza vinculante tal que el producto de su ejercicio, el laudo arbitral, se asimilaba a una decisión de carácter judicial.

Sobre este particular, la Corte se pronunció en los siguientes términos:

En sentencia de 29 de mayo de 1969 (M. P. Dr. Luis Sarmiento Buitrago, G. J. tomo CXXXVII, número 2338, pág. 58), por la cual se declararon exequibles las normas legales a la sazón vigentes sobre procedimiento arbitral y cláusula compromisoria, la Corporación abordó el tema de la naturaleza del acto arbitral, aludiendo a las dos grandes posiciones que se han expuesto sobre el particular: la que lo considera como un acto jurídico de derecho privado, mediante el cual los involucrados en un litigio confían convencionalmente su solución a unos delegados particulares (delegación que se hace a la luz del contrato de mandato) y cuya decisión adquiere fuerza obligatoria por virtud del principio del respeto a la voluntad contractual (...) y la que lo concibe como un acto eminentemente jurisdiccional, en cuanto expresa el ejercicio de una función pública esencial del Estado, que excepcionalmente éste permite a los particulares, a saber, la de impartir justicia cuando las partes no pueden o no quieren poner término a sus diferencias en forma personal y amigable. La Corte, en la sentencia de que se trata, se abstuvo de optar por una u otra teoría, con el considerando de que cualquiera de ellas fundamentaba la declaratoria de exequibilidad de las normas que en ese entonces se encontraban bajo su examen (cs,, Plena, 21 mar. 1991, P. Escobar). 
Pero en esta ocasión la Corte estima imprescindible precisar la naturaleza de la función arbitral y de los actos arbitrales, ya que de ello depende, en su sentir, la definición sobre la exequibilidad o inexequibilidad de la norma acusada, como se verá (csı, Plena, 21 mar. 1991, P. Escobar).

Para posteriormente concluir:

Un tribunal de arbitramento, sin duda alguna, profiere primordialmente actos jurisdiccionales. (...) Los árbitros obran en forma similar a cualquier juez, ya que mediante un procedimiento preestablecido deben comprobar los hechos planteados por las partes, valorar las pruebas aportadas y extraer de este acervo una consecuencia definitoria condensada en un proveído que, formal y materialmente, es revestido de las características de verdadera sentencia, pues se trata de un acto de declaración de certeza del derecho (css, Plena, 21 mar. 1991, P. Escobar).

El escenario descrito permite concluir que la visión contractualista o jurisdiccional del arbitraje y, por consiguiente, las consecuencias prácticas de su alineamiento en una u otra categoría pueden surgir espontáneamente en un idéntico escenario de ausencia de consagración constitucional, por cuenta de la inclinación conceptual del máximo juez de la materia. Lo anterior se advierte y se reafirma con el hecho de que el contenido de las normas estudiadas en ambos casos, leyes 105 de 1931, 02 de 1938 y Decreto 2279 de 1989 respectivamente, no tuvo mayor incidencia en el sentido de las conclusiones adoptadas.
Los antecedentes jurisprudenciales inmediatos al proceso constituyente de 1991 fueron determinantes en las discusiones que sobre el arbitraje ocurrieron en el seno de la Asamblea Nacional que dio origen a la nueva Carta Política.

Desde los primeros debates se observó la voluntad expresa de incorporar el arbitraje en el Texto Constitucional. En ese primer impulso, algunos de los articulados propuestos referían a la posibilidad de que los particulares interviniesen en la administración de justicia a través de las figuras de los "tribunales de conciencia" y de "tribunales de conciliación o arbitramento". Para estos últimos, se recalcaba que podrían proferir fallos en equidad (Asamblea Nacional Constituyente, 1991a).

En debates posteriores, los textos considerados evolucionaron en el sentido de atribuir al legislador una mayor libertad configurativa, ya que la posibilidad que tendrían los particulares de intervenir en la administración de justicia estaría dada en los términos en que determinara la ley (Asamblea Nacional Constituyente, 1991b). En este mismo sentido, pero recalcando que dichos fallos tendrían un control judicial y no estarían sometidos exclusivamente a la equidad, se presentó una proposición sustitutiva que se debatió en el seno de la plenaria del estamento constituyente (Osorio, 2012). Finalmente, y tras haber debatido sobre los posibles alcances indeseados de la norma, en cuanto a que esta otorgaría al legislador un marco regulatorio demasiado amplio, se adoptó una disposición que 
posteriormente se convertiría en el artículo 116 de la Constitución Política, en el cual se advertía sobre la posibilidad de que los particulares pudieren ser transitoriamente investidos de la función de administrar justicia en la condición de árbitros habilitados por las partes para proferir fallos en derecho o en equidad.

En este orden de ideas, el texto originalmente aprobado fue redactado en los siguientes términos, en lo pertinente:

Artículo 116. (...) Los particulares pueden ser investidos transitoriamente de la función de administrar justicia en la condición de conciliadores o en la de árbitros habilitados por las partes para proferir fallos en derecho o en equidad, en los términos que determine la ley.

La citada norma fue modificada parcialmente por el artículo $1^{\circ}$ del Acto Legislativo n. ${ }^{\circ} 03$ de 2002 , en el cual se incluyen como particulares habilitados para tal función a los jurados en causas criminales. Dicha complementación no tuvo incidencia alguna en lo que nos concierne.

Esta tendencia por elevar el arbitraje a rango constitucional y por incluirlo como una modalidad de ejercicio jurisdiccional se fortaleció posteriormente con la expedición de la Ley Estatutaria de Administración de Justicia y luego con la reforma llevada a cabo en 2009. En una primera instancia, el texto original de la Ley 270 de 1996 dispuso:

Artículo 13. Ejercen función jurisdiccional de acuerdo con lo establecido en la Constitución Política: (...) 3. Los particulares actuando como conciliadores o árbitros habilitados por las par- tes, en asuntos susceptibles de transacción, de conformidad con los procedimientos señalados en la ley. Tratándose de arbitraje, las leyes especiales de cada materia establecerán las reglas del proceso, sin perjuicio de que los particulares puedan acordarlas. Los árbitros, según lo determine la ley, podrán proferir sus fallos en derecho o en equidad.

La reforma adelantada en la Ley 1285 de 2009 trajo consigo una serie de modificaciones de gran relevancia en cuanto a la materia arbitrable, y la posibilidad de las partes de escoger las reglas de procedimiento, en los siguientes términos:

Artículo 6. Ejercen función jurisdiccional de acuerdo con lo establecido en la Constitución Política: (...) 3. Los particulares actuando como conciliadores o árbitros habilitados por las partes, en los términos que señale la ley. Tratándose de arbitraje, en el que no sea parte el estado o alguna de sus Entidades, los particulares podrán acordar las reglas de procedimiento a seguir, directamente o por referencia a la de un Centro de Arbitraje, respetando, en todo caso los principios Constitucionales que integran el debido proceso.

Tomando en cuenta los presupuestos constitucionales arriba descritos, así como el desarrollo "cuasi-constitucional" que ha tenido la figura en el plano de la norma estatutaria, se procede a describir los presupuestos "marco" del arbitraje a la luz de la jurisprudencia de la Corte Constitucional, aún aplicable para la actual legislación contenida en la Ley 1563 de 2012, haciendo especial énfasis en las características que ostenta el arbitraje como mecanismo de carácter jurisdiccional y la consagración de mecanismos de 
amparo o tutela constitucional para la protección de derechos fundamentales en este ámbito.

\section{a. El arbitraje como mecanismo de "descongestión de despachos judiciales"}

La sentencia C-592 de 1992 se constituyó en el primer antecedente de pronunciamientos constitucionales por la Corte a la luz de la nueva Carta Política. En aquella ocasión, la Corporación estudió el trámite de la expedición del Decreto 2651 de 1991 y el contenido de sus normas, dentro de las cuales se destacaban los artículos 11 a 20 sobre arbitraje. Resulta de particular interés que la mencionada disposición revestía al presidente de la República de precisas facultades extraordinarias para, entre otras cosas, expedir normas para descongestionar los despachos judiciales, de conformidad con el artículo $5^{\circ}$ transitorio de la Constitución Nacional.

Consideró la Corte que las normas expedidas debían contener formulaciones cuyo objetivo hubiese sido, efectivamente, descongestionar los despachos judiciales, a fin de no entender desbordadas las competencias impuestas al legislador delegado. Para la Corporación, las medidas de descongestión comprenden una variada gama de acciones, de eliminación de pasos judiciales, aligeramiento de otros, redistribución de competencias, o desjudicialización de conflictos jurídicos a fin de que sean asumidos total o parcialmente por particulares o funcionarios no judiciales (CConst., C-592/92, F. Morón).

Sin realizar mayores consideraciones, la Corte reafirmó que los artículos demandados regulaban aspectos atinentes al proceso arbitral y a la investidura transitoria de los árbitros de la función de administrar justicia. Igualmente, apreció que las mencionadas disposiciones contenían una finalidad evidente de simplificación de trámites y una desjudicialización de algunos de ellos, lo que a su parecer consultaba los fines impuestos por el Constituyente, en el sentido de procurar la descongestión de los despachos judiciales.

Del anterior pronunciamiento se desprenden varias conclusiones que llaman particularmente la atención:

Primero, la Corte considera que en el arbitraje subyace una finalidad de simplificación de trámites y de desjudicialización. Esta afirmación parecía abrir la puerta a un sistema de solución de controversias ágil y eficaz, desprovisto de las ataduras propias del proceso judicial. No obstante, con el paso de los años, la jurisprudencia y la práctica arbitral develarían una realidad abiertamente contraria a estos presupuestos.

En segundo lugar, la alta Corporación entendió que, en los términos de la legislación imperante en la época, el arbitraje constituía un sistema tendiente a la descongestión de despachos judiciales. Esta afirmación banaliza las razones estructurales de este fenómeno así como los alcances de este mecanismo alternativo de solución de controversias. Por un lado, es posible afirmar que por la naturaleza voluntaria, onerosa y especializada del arbitraje, su calificación como sistema de descongestión de despachos judiciales es ajena a los impulsos que han hecho de esta figura una institución ampliamente 
reconocida en las legislaciones comparadas. ${ }^{1}$ Por otro lado, es claro que los tipos de procesos que contribuyen especialmente a la congestión no son compatibles con aquellos que se despachan por la vía arbitral.

\section{b. El carácter jurisdiccional del arbitraje y el árbitro como juez}

Desde los inicios de la jurisprudencia constitucional surgida al amparo de la Carta de 1991, la Corte ha hecho particular hincapié en la asimilación de la función del árbitro a la de los jueces de la República, como se verá a continuación.

El primer antecedente lo constituye la sentencia C-426 de 1994, en la que la alta Corporación se refirió a la potestad atribuida a los tribunales de arbitramento en materia estatal para ampliar el término para fallar, inicialmente previsto en la ley o en el acuerdo entre las partes. En esta sentencia, la Corte parece inclinarse hacia una postura contractualista del arbitraje al disponer que tanto las personas privadas en ejercicio de su libre autonomía, cuando contratan entre sí, como las entidades públicas, en la contratación administrativa, pueden pactar la cláusula compromisoria, sometiendo a la decisión de árbitros las eventuales diferencias y los conflictos que puedan surgir en relación con un determinado contrato. Al hacerlo con base en el recíproco consentimiento, radican en cabeza de los árbitros la competencia para resolver sobre las con-

1 En países como Chile en donde el arbitraje se constituye en un mecanismo obligatorio para resolver cierto tipo de controversias, se podría afirmar que este constituye una alternativa válida para la descongestión de despachos judiciales. Sin embargo, esta clase de arbitraje escapa a la órbita de análisis del presente trabajo. siguientes controversias y se obligan a acatar lo decidido por aquéllos (CConst., C-426/94, J. Hernández).

No obstante, la Corte precisa su argumento al referirse a la regla general prevista en el artículo 228 de la Constitución ${ }^{2}$ y manifiesta que los árbitros “-como jueces que son-” están sometidos a los términos impuestos por las normas constitucionales y legales para resolver. En tal sentido, la Corte consideró que los litigios deben llegar a su culminación y que la ley, al fijar unos límites temporales para la actuación de quienes tiene la calidad de jueces, auspicia el principio constitucional en cuya virtud el Estado debe propender por la pronta y cumplida administración de justicia.

Esta afirmación pone de manifiesto que para el juez constitucional los vínculos entre arbitraje y administración de justicia son innegables, al punto de atribuir a este mecanismo alternativo una irrefutable condición de función pública, en la que los árbitros quedan "revestidos de autoridad judicial".

El proveído de la "función pública" es posteriormente reafirmado en la sentencia C-294 de 1995, en la que la Corte Constitucional reconoce incluso la posibilidad de que en el trámite arbitral se ventilen controversias propias del proceso de ejecución en el que se hayan propuesto

2 “ARTICUlo 228. La Administración de Justicia es función pública. Sus decisiones son independientes. Las actuaciones serán públicas y permanentes con las excepciones que establezca la ley y en ellas prevalecerá el derecho sustancial. Los términos procesales se observarán con diligencia y su incumplimiento será sancionado. Su funcionamiento será desconcentrado y autónomo". 
excepciones de mérito. La alta Corporación realiza un paralelo entre las funciones de los tribunales y jueces enumerados en el inciso primero del artículo 116 de la Constitución y los árbitros reconocidos en el inciso cuarto del mismo artículo. En el primer caso, manifiesta que aquellos ejercen una función pública cuya razón de ser está en la existencia misma del Estado. Frente a los segundos, refiere a que también ejercen una función pública pero que, a diferencia de los primeros, tienen que ser "habilitados por las partes para proferir fallos en derecho o en equidad" (CConst., C-294/95, J. Arango).

Esta escalada en la "jurisdiccionalización" del arbitraje por parte de la jurisprudencia constitucional alcanzó un punto bastante alto cuando la Corte, en sentencia C-431 de 1995, se pronunció sobre la posibilidad de que los árbitros decretaran medidas cautelares. El debate sobre el ejercicio de tales potestades resultaba de gran trascendencia pues se confirmó que los tribunales arbitrales ostentan todos los poderes de los jueces, incluido el imperium (CConst., C-431/95, H. Herrera).

En aquella oportunidad, consideró el demandante que los artículos 32 del Decreto 2279 de 1989, 110 de la Ley 23 de 1991 y el inciso 2o. del artículo 2o. del Decreto 2651 de 1991, vulneraban la Constitución Política de Colombia pues admitían que un tribunal nombrado por particulares usurpara una competencia atribuida en forma privativa y excluyente a la justicia ordinaria. Así mismo, manifestó el accionante que el Estado desconocía uno de sus fines esenciales como es el de garantizar la efectividad de
Ios principios, derechos y deberes, ya que el poder coactivo del Estado solo puede ser ejercido por los representantes del pueblo, y un tribunal de arbitramento constituido para un caso concreto no tiene esa calidad.

En este orden de ideas, sostiene el actor que otorgar a los árbitros la facultad de decretar medidas cautelares contraviene las normas superiores que consagran la soberanía, de la cual emana el poder público, y que en su decir pertenece al Estado y no a particulares, así ejerzan funciones jurisdiccionales de manera temporal. Aclara, además, que al tener la facultad de conocer y juzgar las controversias cuya decisión se les encomienda, los árbitros ejercen jurisdicción, pero no pueden ordenar por sí mismos el empleo de la fuerza coactiva del poder público, que compromete siempre los intereses sociales, ya que han sido investidos privadamente y no por el Estado (CConst., C-431/95, H. Herrera).

La decisión de la Corte resultó en cierta forma previsible, por cuenta de las fórmulas previstas en los preceptos constitucionales. En efecto, manifestó esta Corporación que no obstante que el arbitraje se origina en un negocio jurídico privado, quien le otorga la facultad de administrar justicia a los particulares en la condición de árbitros es la misma Constitución Política. Dicha habilitación, sostiene la Corte, es transitoria, pero los árbitros obran en forma similar a cualquier juez, con los mismos poderes. En este orden de ideas, afirma que la existencia del pacto arbitral sustrae o excluye el negocio sometido a arbitraje de la competencia de la jurisdicción ordinaria y la sustituye. 
Respecto de las medidas cautelares, la Corte reiteró su carácter instrumental, su vigencia provisional y resaltó especialmente su carácter jurisdiccional, en cuanto son actos o instrumentos propios de un proceso que permiten al juez adoptar medidas para garantizar la satisfacción de un derecho material, o para su defensa a lo largo del proceso.

Por otro lado, para justificar su adopción en el curso del trámite judicial, enunció que son poderes de los jueces:

a) El poder de decisión, por medio del cual resuelven con fuerza obligatoria la controversia. b) El poder de coerción, mediante el cual se procuran los elementos necesarios para el cumplimiento de la decisión. c) El poder de documentación o investigación, en virtud del cual se le otorga la facultad de decretar y practicar pruebas, ya sea de oficio o a petición de parte, para llegar con la valoración de ellas, a una verdad real y de esa forma poder adoptar la decisión que en derecho corresponda, y d) El poder de ejecución, que está íntimamente ligado con el de coerción, pero que tiene su propio sentido, pues si bien implica el ejercicio de coacción y aún de la fuerza contra una persona, no persigue facilitar el proceso sino imponer el cumplimiento de un mandato claro y expreso, sea que se derive de una sentencia o de un título proveniente del deudor y al cual la ley le asigne ese mérito (CConst., C-431/95, H. Herrera).

Así las cosas, concluye la Corte que el Texto Fundamental otorga al legislador la facultad de limitar o ampliar el ámbito de competencia de los árbitros mediante la fijación de un procedimiento pertinente. Para lo anterior, considera el alto tribunal que si el juez ordinario en su tarea de administrar justicia goza de la facultad de decretar medidas cautelares, igualmente lo puede hacer el árbitro dada su investidura de administrador de justicia. En este sentido, reitera que los árbitros podrán decretar medidas cautelares a efectos de materializar el poder de coerción que permite hacer efectivas sus decisiones y que por ello no usurpan la competencia de la justicia ordinaria, por cuanto estos poderes no le son exclusivos.

De lo anteriormente expresado se deriva que en este estado de la jurisprudencia la asimilación del árbitro al juez resulta incontestable, por lo que los rasgos que esencialmente los distinguen son: 1) La necesidad de contar con la habilitación de las partes; 2) La temporalidad en el ejercicio de sus funciones; y 3) El carácter oneroso de la figura, temática abordada en profundidad en la sentencia C-451 de 1995.

Para complementar esta caracterización, la sentencia C-1436 de 2000 recogió la temática de las limitaciones que encuentran los poderes de los árbitros en el escenario de la solución de controversias con entidades públicas. Si bien se ha resaltado a lo largo del presente escrito que la condición de los árbitros es equiparable a la de los jueces, con las limitantes temporales y materiales que las normativas constitucionales, estatutarias y legales han dispuesto, la jurisprudencia $^{3}$ se ha encargado igualmente de imponer fronteras cuando de arbitraje estatal se trata.

3 Revisar, en este mismo sentido: Corte Constitucional de Colombia. Sentencia C-098 de 2001. M. P. Martha Victoria Sáchica: 31 de enero de 2001. 
En el caso de este pronunciamiento, se demandó la inconstitucionalidad de los artículos 70 y 71 de la Ley 80 de 1993, ya derogados, por ir en contravía del artículo 29 de la Constitución, el cual enseña que los procesos se deben resolver por el juez competente, siendo competente, de manera exclusiva y excluyente, la jurisdicción de lo contencioso administrativo para conocer todo lo referente a los actos administrativos, en sus efectos jurídicos y sus efectos económicos.

Insistió el demandante en que ello aparecía claro en los artículos 236 a 238 de la Constitución, de donde se infiere que respecto al acto administrativo el juez natural es la jurisdicción de lo contencioso administrativo. En ese orden de ideas, cuando los citados artículos del estatuto de contratación estatal permitían a los particulares, en condiciones de árbitros, pronunciarse incluso sobre los actos administrativos contractuales proferidos en uso de las facultades exorbitantes de la administración, se vulneraban los presupuestos constitucionales antes citados.

Por su parte, la Corte manifestó que la competencia de los árbitros no solo tenía límites temporales sino materiales dados por la naturaleza del asunto sometido a su conocimiento. En este sentido, identificó que solo aquellas materias susceptibles de transacción podían ser definidas por los árbitros, por lo que los particulares investidos de la facultad de administrar justicia no podían pronunciarse sobre asuntos que involucraran "el orden público, la soberanía nacional o el orden constitucional, asuntos que en razón de su naturaleza, están reservados al Estado, a través de sus distintos órganos" (C-1436/00, A.
Beltrán). Valga anotar que al día de hoy la arbitrabilidad objetiva no está definida en términos de transigibilidad pues la reforma a la Ley Estatutaria de Administración de Justicia y la Ley 1563 de 2012 dejaron de lado el mencionado criterio.

Bajo estas premisas, el juez constitucional entendió que los árbitros nombrados para resolver Ios conflictos suscitados como consecuencia de la celebración, el desarrollo, la terminación y la liquidación de contratos celebrados entre el Estado y los particulares no tenían competencia para pronunciarse sobre los actos administrativos dictados por la administración en desarrollo de sus poderes excepcionales.

\section{c. El arbitraje como proceso y el laudo como sentencia judicial}

Consecuencia casi que ineludible del tratamiento constitucional del arbitraje como mecanismo jurisdiccional y del árbitro como funcionario judicial transitorio es el relativo a la naturaleza del trámite adelantado y al laudo dictado en este ámbito, como se verá a continuación.

La sentencia C-330 de 2000 desarrolló el debate sobre la regulación del arbitraje en materia laboral y la posibilidad de suscribir pactos arbitrales entre empleados y empleadores; en ella la Corte Constitucional se refirió a esta institución en el plano del derecho procesal y a su asimilación a los procedimientos que se adelantan ante la jurisdicción permanente.

En tal sentido, el juez constitucional manifestó que, en nuestro ordenamiento jurídico, la insti- 
tución arbitral tiene el carácter de un proceso, puesto que en él se garantizan los derechos de las partes enfrentadas a través de una serie de oportunidades en las que se discuten los argumentos, se valoran las pruebas y se someten a consideración de los jueces permanentes las decisiones tomadas por los árbitros.

Insistió esta Corporación en que el arbitraje es "un verdadero procedimiento judicial -en sentido material-", razón por la cual "está sometido en todas sus etapas a la estricta aplicación de las normas que regulan este tipo de actuaciones tanto desde el punto de vista formal como material" (CConst., C-330/00, C. Gaviria). Valga aclarar que lo afirmado por la Corte en este pronunciamiento, en consonancia con la sentencia C-037 de 1996, sentó las primeras bases para el desteñido debate sobre la posibilidad de que los particulares fijen reglas de procedimiento en los trámites arbitrales, aparentemente superado por virtud del artículo 58 de la Ley 1563 de 2012.

Evidentemente, la asimilación del arbitraje a un proceso judicial en sentido "formal y material" parece intuir la necesidad de aplicar en él todas y cada una de las formas que gobiernan los procesos civiles. Sin embargo, a pesar de su innegable asimilación a un proceso, a la Corte parece bastarle con que se garanticen los presupuestos básicos del debido proceso, al concluir que:

Se trata de un mecanismo en el que han de aplicarse con rigor las garantías del debido proceso aplicables a toda actuación judicial, pues de nada sirve la inclusión de mecanismos de solución de litigios, adicionales y alternativos al sistema ordinario contemplado en la legislación, si su aplicación se traduce en el desconocimiento de derechos constitucionales fundamentales (CConst., C-330/00, C. Gaviria).

Por último, en lo que al carácter jurisdiccional del arbitraje y a la naturaleza eminentemente procesal del trámite se refiere, la sentencia C-1038 de 2002 constituyó un hito al analizar la constitucionalidad de una serie de normas que disponían la estructura del "proceso arbitral".

Desde el punto de vista regulatorio, las normas estudiadas organizaban el arbitraje bajo un esquema muy similar al concebido para los procedimientos adelantados en la jurisdicción civil. Adicionalmente, esta normativa contenía múltiples referencias a instituciones del procedimiento civil que complementaban el funcionamiento del trámite. No obstante, las disposiciones acusadas involucraban la participación de los directores de los centros de arbitraje en una serie de etapas destinadas a establecer la relación jurídico-procesal (traba de la litis), como eran las relativas a la admisión de la demanda, las notificaciones, la celebración de audiencias de conciliación, etc.

Para la Corte, esta Ilamada "etapa prearbitral" era de gran trascendencia, pues no solo incluía actos "procesales y materiales" necesarios "para la conformación ulterior del Tribunal", sino que además en esa fase al director del Centro de Arbitraje incumbía ejercer poderes procesales que traslucen una clara e indubitable función pública como son los relacionados con las 
diligencias de notificación, admisión y rechazo de la solicitud de convocatoria, decisión de los recursos de reposición, conducción de la audiencia de conciliación etc. (CConst., C-1038/02, E. Montealegre).

Invoca el alto tribunal la tesis sostenida por la Sección Primera del Consejo de Estado en Auto del 7 de diciembre de 2000, en el que el máximo órgano de lo contencioso administrativo concluyó que el trámite "prearbitral" era de naturaleza jurisdiccional, por lo que en su momento resolvió que carecía de control sobre ese ente. El argumento del Consejo de Estado, invocado por el tribunal constitucional, consistía en que las actuaciones del centro de arbitraje tenían naturaleza judicial, no solo porque estaban destinadas a impulsar el proceso arbitral, sino además por cuanto, en su fondo y forma, estaban sometidas a lo previsto en el estatuto procesal civil para los procesos judiciales.

En consecuencia, tras admitir que resulta de gran complejidad identificar los criterios para distinguir una función judicial de una función administrativa, la Corte consideró que existían algunos elementos formales y materiales útiles para dirimir esa controversia. En lo relativo a los criterios formales, encontró que son funciones judiciales: 1) las que se materializan en actos con fuerza de cosa juzgada; 2) las que son desplegadas por jueces o por funcionarios con esa categoría; y 3) las que se desarrollan en el marco de procesos judiciales. Y desde una perspectiva material, que tienen tal categoría las funciones que determinan una limitante al derecho al libre acceso a la administración de justicia.
Tras analizar y cotejar la normativa vigente con la disposición constitucional consagrada en el artículo 116, el alto tribunal encontró que la norma superior atribuía el ejercicio de funciones jurisdiccionales exclusivamente a los árbitros y que las actuaciones propias de un proceso judicial no podían ser adelantadas por operadores diferentes pues eso contrariaba los preceptos constitucionales sobre la materia. De esta manera, la Corte reformuló la estructura del trámite arbitral y ratificó su naturaleza eminentemente procesal.

Finalmente, en lo que respecta a la naturaleza del laudo arbitral, la Corte Constitucional en sentencia C-242 de 1997 se pronunció sobre el carácter voluntario del arbitraje al declarar inexequible el numeral 19.4 del artículo 19 de la Ley 142 de 1994, régimen de los servicios públicos domiciliarios, por considerar que la ley no podía reemplazar la libre voluntad de las partes de recurrir a este sistema de solución de controversias.

Tras un análisis sobre los límites materiales y temporales del arbitraje, el principio de habilitación como fundamento de su procedencia y la reiteración de su carácter jurisdiccional, entre otros, la Corte se refiere al punto del laudo arbitral como instancia culminante de la función jurisdiccional desplegada. A estos efectos, considera que la decisión arbitral, concretada en el laudo, tiene un carácter eminentemente jurisdiccional y equivale a una providencia judicial, en cuanto en él se analizan los hechos, se hace una valoración probatoria, se resuelven las pretensiones y se declara el derecho a la luz de los 
mandatos constitucionales y legales o atendiendo a los principios de equidad, según el caso.

Concluye la Corte que si bien la ejecución y control de ese laudo corresponde a la jurisdicción permanente, no cabe duda alguna de que el arbitraje se constituye en una institución para lograr una eficaz administración de justicia.

\section{d. La acción de tutela contra las decisiones arbitrales}

Sin pretender desarrollar esta temática a fondo, pues no corresponde a la oportunidad del presente trabajo, resulta claro a la luz de la jurisprudencia colombiana la procedencia de las acciones constitucionales de amparo contra laudos y decisiones de los tribunales de arbitramento, dadas las características de estamentos jurisdiccionales que los presupuestos constitucionales, legales y jurisprudenciales les han atribuido.

Por tanto, además del recurso de anulación, mecanismo de impugnación que los instrumentos internacionales de unificación y armonización - Ley Modelo de la CNUDMI ${ }^{4}$ - consagran para el arbitraje, el carácter eminentemente jurisdiccional de esta figura en Colombia abre las puertas a la procedencia de mecanismos adicionales de control. Es el caso del recurso de revisión ${ }^{5}$ y la

4 Comisión de las Naciones Unidas para el Derecho Mercantil Internacional.

$5 \quad$ Ley 1563 de 2012. "ARTículo 45. RECURSO DE REVISIÓN. Tanto el laudo como la sentencia que resuelva sobre su anulación, son susceptibles del recurso extraordinario de revisión por las causales y mediante el trámite señalado en el Código de Procedimiento Civil. Sin embargo, quien tuvo oportunidad de interponer el recurso de anulación no podrá alegar indebida representación o falta de notificación. Cuando prospere el recurso de revisión, la autoridad judicial dictará la sentencia que en derecho corresponda". acción de tutela para situaciones en las que a juicio del juez se incurra en vías de hecho que afecten derechos constitucionales fundamentales y no exista ningún otro medio de defensa para resarcirlo. Así mismo, cuando se utilice como un medio transitorio para evitar un perjuicio irremediable.

Ahora bien, también resulta innegable que aunque los presupuestos de las mencionadas acciones constitucionales sean las decisiones que contengan fundamentos arbitrarios, caprichosos o abusivos y que en un principio este se haya contemplado como un mecanismo residual (Ibañez, 2009), en la actualidad la Corte Constitucional ha aceptado la procedencia de esta acción aun encontrándose pendiente y hasta de forma paralela al recurso de anulación, lo que ha llevado a que en muchos casos su utilización haya sido desproporcionada.

Finalmente, dada la posibilidad de que en cualquier escenario del ejercicio de la actividad jurisdiccional se pueda incurrir en vías de hecho, susceptibles de resarcir por vía de estas acciones constitucionales, la Corte Constitucional también ha aceptado la procedencia de las acciones de tutela contra las providencias que resuelven los recursos de anulación, así como los incidentes de nulidad contra decisiones de la misma Corporación en las que se haya debatido, en sede de tutela, un tema originariamente sometido al conocimiento de un tribunal arbitral controlado por vía de esta acción de protección constitucional.

Visto lo anterior, resulta claro que la extensión de mecanismos de control a las decisiones arbi- 
trales que son de naturaleza diversa a los consagrados en los instrumentos internacionales que desarrollan e implementan la materia, deriva en una evidente pérdida de autonomía del arbitraje frente a la jurisdicción permanente. Si bien estos presupuestos resultan plausibles y acordes con la naturaleza eminentemente jurisdiccional que el ordenamiento colombiano le ha atribuido al arbitraje, estos escenarios han añadido mayores componentes de incertidumbre y han redundado en una evidente desmejora de la seguridad y celeridad que este mecanismo persigue.

\section{B. Algunas experiencias del derecho constitucional latinoamericano}

Constitucionalizar el arbitraje no es la única manera de reconocerlo como mecanismo válido y legítimo de solución de controversias, alternativo al sistema jurisdiccional permanente. Como se verá más adelante, en algunos países europeos como España, en los que el desarrollo del arbitraje ha resultado particularmente atractivo, los textos constitucionales no contienen referencia alguna a esta figura.

Sin embargo, en la casi totalidad de los sistemas latinoamericanos el legislador superior optó por incorporar el arbitraje al Texto Fundamental. ${ }^{6}$ Ahora bien, como es evidente, los pro-

6 Los países que en el escenario latinoamericano han reconocido el arbitraje en los textos constitucionales son: Costa Rica, en la Constitución de 1949 (reformada), cuyo artículo 43 establecía que "toda persona tiene derecho a terminar sus diferencias patrimoniales por medio de árbitros, aun habiendo litigio pendiente"; Honduras, con la consagración del artículo 110 de la Constitución de 1982 (reformada), cuyo contenido rezaba que "ninguna persona natural que tenga la libre administración de sus bienes, puede ser privada del derecho de cesos constituyentes que han tenido lugar en el hemisferio derivaron en fórmulas consagratorias de diferente índole, desde el reconocimiento del arbitraje como un mecanismo de solución de controversias con carácter eminentemente jurisdiccional, en el que la función arbitral es asimilable a la de un juez, como en el caso colombiano, hasta fórmulas en las que el arbitraje es entendido y tratado como un derecho fundamental del ciudadano que busca una alternativa efectiva al sistema judicial para terminar sus diferencias de carácter patrimonial.

En este apartado se desarrollan y explican algunas de esas alternativas consagratorias del arbitraje en los textos constitucionales, no con el propósito de realizar análisis comparativos sino con la idea de revisar el desarrollo y alcance que dichas fórmulas han tenido respecto de la práctica arbitral en su entorno particular, enfocados especialmente en la modalidad del arbitraje como derecho y no como estamento judicial, pues esta visión resulta a todas luces la más apartada de las fórmulas consagratorias que, como en el caso de nuestro país, encasi-

terminar sus asuntos civiles por transacción o arbitramento"; El Salvador, con la Constitución de 1983 (reformada), la cual en su artículo 23 asentó que "ninguna persona que tenga la libre administración de sus bienes puede ser privada del derecho de terminar sus asuntos civiles o comerciales por transacción o arbitramiento. En cuanto a las que no tengan esa libre administración la ley determinará los casos en que pueden hacerlo y los requisitos exigibles"; Colombia, en el artículo 116 de la Constitución de 1991 consagró que "los particulares pueden ser investidos transitoriamente de la función de administrar justicia en la condición de conciliadores o en la de árbitros habilitados por las partes para proferir fallos en derecho o en equidad, en los términos que determine la ley"; Panamá, en el artículo 202 de la Constitución del 15 de noviembre de 2004, dispone de forma similar a la Constitución de la República Bolivariana de Venezuela, que la "administración de justicia también podrá ser ejercida por la jurisdicción arbitral conforme lo determine la Ley. Los tribunales arbitrales decidirán por sí mismos acerca de su propia competencia (Fundación Estudios de Derecho Administrativo, 1999). Se añaden a este estudio los casos de Perú (arts. 62 y 63) y Paraguay (art. 248). 
Ilan la figura del arbitraje como un apéndice del Poder Judicial, con las consecuencias prácticas que ello conlleva.

\section{El arbitraje como derecho fundamental}

Algunas constituciones latinoamericanas siguieron la pauta establecida por la Constitución francesa de 3 de septiembre de 1791, que en su artículo $5^{\circ}$ establecía: "el derecho de los ciudadanos de terminar definitivamente sus controversias por la vía del arbitraje no puede ser vulnerado por actos del poder legislativo". En este mismo sentido, la Constitución de Cádiz de 1812 dispuso en su artículo 280 el derecho inalienable de los ciudadanos españoles de "terminar sus diferencias por medio de jueces-árbitros, elegidos por ambas partes" (Hernández-Bretón, 2007, pág. 30).

Ahora bien, la consagración del arbitraje como derecho fundamental puede derivarse de la misma literalidad del Texto Constitucional o bien de la interpretación que los jueces encargados de desarrollarlo le hayan dado a la institución, pese a que en el Texto Superior mismo no se haya empleado dicha fórmula. Dentro de los casos que podemos destacar para ilustrar la primera alternativa, están los textos fundamentales de Costa Rica, El Salvador, Honduras, mientras que en casos como el venezolano, la Constitución no dispone una fórmula similar pero su desarrollo doctrinario y jurisprudencial ha llevado al arbitraje a una categoría de derecho fundamental.

Independiente de lo anterior, para efectos del presente trabajo es necesario precisar que nin- guna de estas alternativas puede garantizar que el funcionamiento del arbitraje, en la práctica, vaya a estar libre de intromisiones indebidas o que su efectivo ejercicio se encuentre plenamente asegurado. Por ello, nos limitaremos a describir algunas de las más importantes características del entorno del arbitraje como derecho fundamental en estos países, para posteriormente reflexionar sobre las consecuencias prácticas que ha traído consigo este tipo de fórmulas.

\section{a. La asimilación "directa" en el Texto Constitucional}

El artículo 43 de la Constitución Política de Costa Rica reconoce el arbitraje como un derecho que ostentan las personas, y la jurisprudencia constitucional ha reconocido su aptitud como mecanismo voluntario y expedito para la solución de conflictos (Gómez y Gómez, 2010). En efecto, el texto del mencionado artículo reza: "toda persona tiene derecho a terminar sus diferencias patrimoniales por medio de árbitros, aun habiendo litigio pendiente".

A primera vista, esta modalidad de constitucionalización del arbitraje parece constituir una fórmula en la que la visión contractualista prevalece sobre la jurisdiccional, por lo que, en principio, el fenómeno de la judicialización tendería a impactar el trámite en una menor medida. En efecto, la consagración del arbitraje como derecho y no como un mecanismo "enquistado" en el sistema judicial aparece como una alternativa en la que su "fuerza" emerge de la autonomía de la voluntad y en la que el sistema regulatorio se debe constituir en un mecanismo para lograr 
su plena efectividad. Sin embargo, esas conclusiones prima facie no pueden ser validadas sin realizar un análisis detallado de las normas imperantes y algunas decisiones judiciales, a partir de las cuales se identifiquen los verdaderos alcances del sistema, integralmente considerado.

Para estos efectos, es menester señalar que en este país centroamericano el entorno legal del arbitraje está compuesto por la Ley de Resolución Alterna de Conflictos y Promoción de la Paz Social (Ley 7727 del 27 de diciembre de 1997), reglamentada en su capítulo IV por el Decreto Ejecutivo n. ${ }^{\circ} 32152$ de 27 de octubre de 2004, en lo que respecta al arbitraje doméstico, y por la Ley 8937 de 2011, en lo que se refiere a la regulación del arbitraje internacional.

Llama particularmente la atención, el hecho de que en Costa Rica las normativas arbitrales han regulado de forma diversa el arbitraje doméstico y el internacional, y el que el legislador asumió un marco normativo "generoso" en el ámbito del arbitraje con elementos extranjeros, fundamentalmente basado en la Ley Modelo de la cNUDm. No obstante, en lo que respecta a la práctica arbitral doméstica, algunos autores han destacado la visión particularmente "judicializada" que existe del arbitraje, al punto que dichas prácticas se han extendido, incluso, al arbitraje internacional.

Sobre el particular, Eduardo Silva Romero (2011), ex consejero adjunto, consejero y secretario general adjunto de la Corte Internacional de Arbitraje de la Cámara de Comercio Internacional (ccl), escribió:
En América Latina, y en Costa Rica en particular, el arbitraje doméstico y el procedimiento judicial se regulan por normas muy similares e impregnadas de un gran formalismo. Los tribunales y los practicantes del arbitraje en estos países, en consecuencia, acostumbran a que en el arbitraje, tanto doméstico como internacional, se apliquen las formas procesales, algunas veces en extremo rígidas, del proceso judicial (...) resulta de temer entonces que los tribunales insistan en aplicar rigurosamente las reglas que conocen y utilizan en el arbitraje internacional (p. 843).

No obstante, esta visión sobre la práctica arbitral costarricense no es del todo compartida por algunos comentaristas locales, dentro de los que se destaca Dyalá Jiménez Figueres, quien sobre el particular expresa:

Si bien es cierto que existen abogados y árbitros costarricenses que acostumbran seguir las normas de los procesos judiciales locales, esta no es la regla general. Por el contrario, en ciertas ocasiones en los arbitrajes domésticos los árbitros demuestran bastante imaginación. La coexistencia de estas dos prácticas puede explicarse por el hecho de que el arbitraje internacional se ha desarrollado lentamente en Costa Rica y por ende la adopción de las prácticas standards en el ámbito internacional que aseguran un equilibrio entre el formalismo y la flexibilidad aún no se ha generalizado (s.f.).

Esta dicotomía, puesta en evidencia por la referida autora, se hace patente al revisar algunas disposiciones de las normas locales y jurisprudencia de la Corte Suprema de Justicia de ese país. En primera instancia, Ilama la atención el artículo 39 de la Ley 7727 de 1997, en el cual 
se establecen los principios que rigen la actuación arbitral, en el sentido de que las partes podrán escoger libremente el procedimiento que regulará el trámite, siempre que se respeten los principios del debido proceso, el derecho de defensa y el de contradicción; igualmente, señala el referido artículo que el tribunal arbitral, a falta de acuerdo de las partes, deberá dirigir el arbitraje guiado por los principios de "contradicción, oralidad, concentración e informalidad" y que las normas procesales de la legislación costarricense "integrarán, en lo que resulte compatible, el procedimiento arbitral".

Esta norma hace evidente la intención del legislador de permitir un sistema de solución de controversias en el que la autonomía de la voluntad y la informalidad tengan una especial preeminencia, pese a que llame particularmente la atención el vínculo que el legislador hace con la normativa procesal.

Por otro lado, encontramos que en un sentido similar se pronunció la Sala Primera de la Corte Suprema de Justicia del país en comento, mediante Decisión n. ${ }^{\circ}$ 000594-F-00, de 11:40 horas de 18 de agosto de 2000, donde dejó claro el principio de la independencia judicial frente al arbitraje y reconoció la viabilidad de un sistema normativo diferente al Código Procesal Civil, en los siguientes términos:

En primer lugar debe tomarse en cuenta que el legislador se propuso desjudicializar en lo posible el arbitraje, para que fuese efectivamente una alternativa a la justicia institucional. Consecuente con ello, es la prohibición de que los órganos judiciales puedan ser designados árbi- tros de equidad o de derecho (art. 25). En segundo lugar, para potenciar el arbitraje no sólo se le sustrajo del Código Procesal Civil, donde no era sino un procedimiento más, sino que se autorizó a las partes para elegir libremente el procedimiento idóneo frente a la naturaleza del conflicto suscitado, con la única limitación de respetar los principios constitucionales de derecho de defensa y de contradicción (art. 39). En suma la asignación de nuevas competencias a la Sala no puede ser entendida sino como la única injerencia permitida por el legislador a los tribunales en una institución concebida para potenciar una alternativa real a la Administración de Justicia impartida por los órganos judiciales [cursivas añadidas].

Visto lo anterior, encontramos que a pesar de la consagración del arbitraje como derecho en la Constitución Política de 1949, el tratamiento legislativo otorgado a la figura en el plano doméstico ha transcurrido básicamente en dos grandes etapas: la primera como una institución de carácter procesal, integralmente regulada en el Código Procesal Civil; y la segunda, a partir de la expedición de la Ley 7727 de 1997, como un instrumento de solución de controversias flexible cuyas cargas procesales resultan de menor intensidad.

En este último escenario se ha entendido que las partes y los árbitros, a la hora de establecer los procedimientos a seguir, deben ser respetuosos en el cumplimiento de una serie de etapas que garantizan el debido proceso, el derecho de defensa, el principio de contradicción, el principio de inmediación, el principio de concentración, el sistema de oralidad y el principio de informalidad. 
Para un sector de la doctrina, el cumplimiento de las referidas etapas no significa que la regulación pertinente sea considerada una expresión inequívoca de procesalismo. De manera específica, las fases que componen el trámite arbitral son: a) La destinada a la formulación de pretensiones y aporte de pruebas; b) El término para contestar a esas pretensiones y oponerse a los hechos y fundamentos de la demanda; c) La relativa a la evacuación de pruebas con la participación de las partes y de los árbitros; d) El término razonable para la formulación de conclusiones; y e) La instancia para recurrir el laudo arbitral y las resoluciones interlocutorias. Lo anterior, en palabras de Gómez y Gómez (2010) no significa "una intromisión indebida por parte del Estado, que podría llevarnos a pensar que no existe el deseo de desjudicializar el arbitraje" (pág. 309).

Visto lo anterior, podemos entender que la consagración del arbitraje como derecho fundamental, en el caso de Costa Rica, no ha garantizado integralmente la separación entre el trámite arbitral y las normas procesales. Si bien el alcance de las normas vigentes ha significado un avance importante frente a las disposiciones que regulaban el arbitraje en el Código Procesal, es claro que en la práctica algunas instituciones del procedimiento civil siguen estando presentes mediante su utilización por las partes o por los árbitros como instrumentos auxiliares para el desarrollo del trámite, o a través del reconocimiento por la misma normativa, de una serie de etapas ineludibles que escapan incluso a la libre disposición de los contratantes.
Otro caso de consagración del arbitraje como derecho fundamental en el Texto Constitucional, que genera particular interés en el ámbito latinoamericano, es el de El Salvador, donde el artículo 23 de la Carta Política dispone:

Se garantiza la libertad de contratar conforme a las leyes. Ninguna persona que tenga la libre administración de sus bienes puede ser privada del derecho de terminar sus asuntos civiles o comerciales por transacción o arbitramento. En cuanto a las que no tengan esa libre administración, la ley determinará los casos en que puedan hacerlo y los requisitos exigibles.

En el plano legal, se aprobó la Ley de Mediación, Conciliación y Arbitraje de 2002, en un intento por promover la utilización de este mecanismo que estuvo contemplado dentro del derecho procesal común por más de cien años, pero con poco impacto práctico en términos de su uso por parte de los actores económicos de la nación centroamericana. En efecto, las disposiciones derogadas contenidas en el Código de Procedimientos Civiles, en el Código de Comercio y en la Ley de Procedimientos Mercantiles no tuvieron gran aceptación para la solución de conflictos, debido a que la mencionada normatividad hacía indispensable la intervención judicial desde el nombramiento y juramentación de los árbitros hasta la ejecución del laudo arbitral, haciendo de este trámite uno más complejo y extenso que el mismo procedimiento judicial ordinario (Fundación Salvadoreña para el Desarrollo Económico y Social [FUSADES], 2005).

Ahora bien, la adopción del nuevo cuerpo normativo, en consonancia con los términos de la 
Carta Política de 1983, no pareció alcanzar los resultados esperados en términos de promoción de este mecanismo alternativo. Para el año 2005, esto es, doce años después de promulgada la norma, algunas instituciones locales alertaban sobre resultados poco alentadores y sentimientos generalizados de que el arbitraje no era una vía que ofreciera verdaderas ventajas y seguridad a los ciudadanos (FUSADES, 2005). Esta visión pareció ratificarse cuando la Asamblea Legislativa de la República, en una decisión controversial, consideró que era necesario permitir que el laudo arbitral pronunciado en los arbitrajes en derecho pudiera ser apelado con efecto suspensivo ante las Cámaras de Segunda Instancia, por lo que dictó el Decreto Legislativo n. $^{\circ} 141$ del primero de octubre de 2009, en tal sentido. ${ }^{7}$

Dicha postura del constituyente resulta a todas luces contraria a los principios generales que inspiran la función arbitral, pues la posibilidad de permitir un recurso de esa naturaleza en sede judicial desvirtúa íntegramente la razón de ser del arbitraje de acceder a una decisión final y definitiva emanada de uno o varios árbitros seleccionados por las partes o sus delegados en razón de sus específicas condiciones personales y profesionales.

7 "Art. 66-A.- El laudo arbitral pronunciado en el arbitraje en derecho es apelable con efecto suspensivo, dentro de los siete días hábiles siguientes a la notificación del mismo o de la providencia por medio de la cual se aclara, corrige o adiciona, para ante las Cámaras de Segunda Instancia con competencia en materia civil, del domicilio del demandado o el de cualquiera de ellos si son varios.

En los demás, en cuanto a la tramitación del recurso se estará en lo aplicable, a lo regulado por el derecho común.

Contra la providencia de la Cámara de Segunda Instancia no cabrá recurso alguno".
Adicionalmente, el contexto de la jurisprudencia constitucional salvadoreña, en lo referente a la renuncia al recurso de apelación, no constituía un precedente alentador. En efecto, en sentencia del 15 de febrero de 2002, proceso de inconstitucionalidad 9-97, la Sala de lo Constitucional de la Corte Suprema de Justicia manifestó:

Más bien -y como ya expuso-, tal disposición sólo puede referirse a una renuncia previa como garantía de una de las partes frente a la otra de que, independientemente del contenido de la sentencia futura, no se apelará de la misma, terminándose por esa razón el proceso en el primer grado de conocimiento; y es ahí donde estriba la incompatibilidad del ord. $2^{\circ}$ del art. 986 C. Pr. C. con la Constitución, pues la disposición le da crédito procesal a un acuerdo hecho frente a supuestos procedimentales inciertos, los cuales si eventualmente resultaren arbitrarios, ilegales o inconstitucionales, tendrían que dejarse de atacar por ese pacto previo; y ello no es posible constitucionalmente, pues sería restarle fuerza y plenitud al contenido esencial del derecho a la protección jurisdiccional, impidiendo, como señaló la jurisprudencia emanada de las relacionadas sentencias de amparo, "una adecuada tutela y la consiguiente salvaguardia de los derechos de los particulares, provocando un estado de indefensión y de desigualdad para una de las partes".

A lo que agregó:

No puede decirse, entonces, que son per se inconstitucionales las concreciones legislativas referidas a la posibilidad de disponer -vía renuncia o pacto- "derechos procesales" o categorías integrantes del debido proceso, pues en 
algunas ocasiones entra en juego la autonomía de la voluntad o la pronta justicia; sin embargo, no obstante las dos razones anteriores, habrá inconstitucionalidad cuando la renuncia implique violación directa o indirecta al contenido esencial de alguno de aquellos derechos; contenido esencial que encierra finalidades proclamadas por la misma Constitución.

Este antecedente de la jurisprudencia salvadoreña planteó serios interrogantes entre quienes entendieron que la reforma constitucional que implantó el recurso de apelación en el arbitraje significaba un retroceso.

En virtud de lo anterior, el Decreto Legislativo n. ${ }^{\circ} 141$ arriba mencionado fue demandado en sede de constitucionalidad; los argumentos planteados en dicha acción catalogan este recurso como un escollo que torna el arbitraje en una figura inoperante y poco efectiva en términos de los objetivos que teóricamente persigue.

Por su parte, la Sala de lo Constitucional de la Corte Suprema de Justicia en sentencia 112010, al cotejar la mencionada disposición con el artículo 23 de la Carta Política, optó por una solución que, desde nuestro punto de vista, ni salvaguardó el presupuesto de que el arbitraje es un mecanismo que permite resolver controversias de manera definitiva, ni protegió la plena efectividad del principio de autonomía de la voluntad en lo referente a una posible renuncia al instrumento de impugnación.

En efecto, llaman la atención los argumentos de la Sala en el sentido de que el derecho de las partes de "terminar sus asuntos civiles o co- merciales por transacción o arbitramento" no se veía afectado por cuenta de la posibilidad de concurrir a los tribunales ordinarios para revisar, en sede de apelación, el laudo arbitral. Consideró la Corte que "Ios árbitros representan un método adjudicativo, cuya finalidad es resolver las controversias que las partes les plantean. Por ello, proveído el laudo, los árbitros dan cumplimiento a su cometido principal: dirimir el conflicto". Y agrega:

El trámite que supone dicha forma de resolución de controversias queda agotado con la suscripción de la citada resolución y, por tanto, finalizada la etapa arbitral. A partir de este momento, comenzará una labor de colaboración por medio de la etapa de control, la cual es llevada a cabo por el Órgano Judicial, específicamente de las Cámaras de Segunda Instancia de la Capital (css, sentencia 11-2010/11).

Para concluir que "el establecimiento legislativo del recurso de apelación en contra del laudo pronunciado por los árbitros de derecho no impide que estos realicen la función que los interesados le han encomendado" (cs), sentencia 11-2010/11).

Por otro lado, menciona la Sala que en el caso particular existe un amplio marco para la aplicación de la autonomía de la voluntad, por lo que entiende que es permitido a las partes estipular cláusulas orientadas, por una parte, a no acceder al recurso de apelación y, por otra, a condicionar el planteamiento de este al cumplimiento de determinados requisitos. Para algunos comentaristas, estos presupuestos determinaron un cambio de línea jurisprudencial mantenida 
desde hace más de quince años por la Sala, ya que, como quedó establecido en la sentencia arriba referida, el máximo tribunal constitucional había declarado inexequible la renuncia anticipada de derechos fundamentales o garantías de contenido procesal como el recurso de apelación (García, 2012). No obstante, en la decisión de la Sala Constitucional se evidenció una postura con un alto contenido político al establecer que los laudos emitidos en derecho eran recurribles por medio de la apelación, a menos que exista un pacto en contrario, pero únicamente cuando se trate de arbitraje entre particulares.

Llama particularmente la atención el hecho de que ni las normas que regulan el arbitraje, ni el Decreto $n .^{\circ} 141$, demandado, establecen una distinción en el tratamiento de la figura cuando se trata de arbitraje entre particulares o en los casos en que el Estado tenga participación. No obstante, aseguró la Sala que:

La necesidad de que existan medios de impugnación en sentido estricto mediante los cuales se revisen los laudos arbitrales, obedece a una exigencia constitucional que se traduce en la conveniencia de evitar la existencia de zonas exentas de control en la actuación de los tribunales de arbitraje. $Y$ es que, en este punto, habrá de recordarse que el principio de exclusividad jurisdiccional presupone ineludiblemente, no la exclusión de que otros entes distintos al judicial puedan resolver los conflictos, sino la posibilidad de que sea la jurisdicción estatal la que, en última instancia, revise las decisiones emitidas en el sistema de arbitraje.
Esta providencia deja abiertos una serie de interrogantes ya que el arbitraje como derecho fundamental, en los términos del artículo 23 de la Constitución Nacional, parecía lograr altos niveles de independencia frente al sistema judicial, circunstancia esta que ni por vía del desarrollo normativo ni por cuenta de las decisiones jurisprudenciales ha parecido alcanzar en la práctica. En efecto, la libertad, concretada en términos de la autonomía de la voluntad para que las personas puedan someter sus diferencias a este mecanismo de solución de conflictos, pareció doblegarse ante una visión acaparadora de la función de administración de justicia del Estado que interpretó esa alternativa más como un "permiso estatal" que como un verdadero derecho de rango superior.

Por otro lado, es menester resaltar que la concepción del arbitraje como derecho fundamental parece revestir alcances diferentes en cuanto a autonomía cuando de otros sistemas latinoamericanos se trata. En el caso de la normativa hondureña, encontramos que la consagración constitucional de esta figura se concibe en términos similares a la Carta Política de El Salvador, al señalar lo siguiente: “Artículo 110. Ninguna persona natural que tenga la libre administración de sus bienes, puede ser privada del derecho de terminar sus asuntos civiles por transacción o arbitramento". Dicho precepto hunde sus raíces en el derecho a la libertad y más específicamente a la libertad de contratación, consagradas en los artículos 70 y 331 de la Constitución Nacional, respectivamente. En el plano reglamentario, este país centroamericano dispuso en el Decreto 161 de 2000 sus 
normas sobre conciliación y arbitraje, disposición en la que abordó tanto el arbitraje interno como el internacional.

En la mencionada normativa, destacó el legislador en su artículo 36 la plena autonomía de los tribunales arbitrales en las controversias que se resuelvan con sujeción a dicha ley, reafirmando que solo tendrá competencia el tribunal arbitral correspondiente; de esta manera, se limitan los espacios de intervención a cualquier otro tribunal o instancia diferente. Adicionalmente, dispone el decreto en mención la figura de la autoridad judicial de apoyo, quien deberá brindar soporte a los tribunales arbitrales para el ejercicio de sus funciones, especialmente en cuestiones cautelares. Cabe destacar que esta modalidad de ejercicio cooperativo entre los tribunales arbitrales y la jurisdicción es propio de los sistemas de arbitraje internacional y ha sido trasladado al escenario doméstico en la mayoría de los ordenamientos, no así en el colombiano en el que se otorga al árbitro todos los poderes conferidos a los jueces, por lo que este soporte no resulta pertinente.

Ahora bien, Ilama la atención el tratamiento que el ordenamiento jurídico hondureño otorga al arbitraje desde la perspectiva de los controles constitucionales a las decisiones de los árbitros. En efecto, si bien la Constitución de la República y el Decreto 244 de 2003 -Ley sobre Justicia Constitucional- establecen la procedencia del recurso de amparo cuando resulten vulnerados los derechos fundamentales de las personas por cuenta de la actuación de los funcionarios públicos pertenecientes a cualquier órgano de poder del Estado, se estima que dichas acciones no tienen cabida frente a las decisiones tomadas en el seno de los tribunales arbitrales.

Lo anterior, por cuanto se ha considerado que si bien el arbitraje y el ejercicio de la administración de justicia estatal comparten una serie de características similares, estas dos instancias no son asimilables, ya que el arbitraje no conlleva el ejercicio de potestades estatales. En este orden de ideas, la acción de amparo en contra de las decisiones tomadas en el entorno del trámite arbitral solo resulta procedente respecto de las decisiones emanadas de la Corte de Apelaciones cuando conoce del recurso de nulidad y en su actuación infringe alguna norma constitucional en detrimento de alguna de las partes que concurrió al arbitraje (Lobo y Lobo, 2010).

\section{b. La asimilación "indirecta" del arbitraje como derecho fundamental}

La concepción del arbitraje como derecho fundamental en el ordenamiento jurídico venezolano no se desprende del tenor literal del Texto Superior sino de la interpretación que del mismo ha hecho la doctrina y la jurisprudencia de ese país. Ahora bien, es de resaltar que el artículo contentivo de este mecanismo se encuentra dentro del Capítulo III -Del Poder Judicial y del Sistema de Justicia- Sección Primera: Disposiciones Generales y reza: “Artículo 258. La ley promoverá el arbitraje, la conciliación, la mediación y cualesquiera otros medios alternativos para la solución de conflictos".

Las finalidades y alcance de esta particular fórmula de consagración del arbitraje en el Texto 
Constitucional fueron plasmadas en la exposición de motivos de la Constitución de la República Bolivariana de Venezuela (2000), la cual dispuso:

Se incorporan al sistema de justicia, los medios alternativos para la resolución de controversias, tales como el arbitraje, la mediación y la conciliación, todo ello con el objeto de que el Estado los fomente y los promueva sin perjuicio de las actividades que en tal sentido puedan desarroIlar las academias, universidades, cámaras de comercio y la sociedad civil en general.

En este mismo sentido, la Sala Constitucional del Tribunal Supremo de Justicia, haciendo referencia a este deber de promoción del arbitraje, agregó que:

No se agota o tiene como único destinatario al legislador (Asamblea Nacional), sino también al propio operador judicial (Poder Judicial), en orden a procurar y promover en la medida de lo posible la utilización de los medios alternativos de resolución de conflictos y adoptar las medidas judiciales necesarias para promover y reconocer la efectiva operatividad de tales medios, lo cual implica que las acciones típicas de la jurisdicción constitucional, no sean los medios idóneos para el control de los procedimientos y actos que se generen con ocasión de la implementación de los medios alternativos de resolución de conflictos (TSs, Constitucional, expediente $n .^{\circ}$ 08-0763, L. Morales).

Es así como un sector de la doctrina ha entendido que al ser el arbitraje un mecanismo definido en la Constitución como parte integrante del sistema de administración de justicia, este tiene el carácter de derecho fundamental pues materializa el derecho de acceso al sistema de justicia, en el que se tutelan de manera efectiva los intereses de los ciudadanos. En virtud de lo anterior, al garantizarse por vía constitucional el derecho de acceso al arbitraje, se desprende que la idea del constituyente es tutelar de manera efectiva el derecho de quienes opten por acudir a él, por lo que cualquier acto obstructivo emanado del poder público que tienda a menguar o hacer ineficaz la solución de conflictos por esta vía resultaría contrario al principio de progresividad de los derechos reconocido en el artículo 19 de la Carta Política venezolana (Centro de Investigaciones Jurídicas. Academia de Ciencias Políticas y Sociales, 2013).

En esta línea de pensamiento se ha hecho patente que la consagración del arbitraje bajo una fórmula de la que se deriva su carácter de derecho fundamental es de tal trascendencia que potencializa las relaciones entre la jurisdicción “permanente" y la justicia arbitral, generando así un marco de mayor colaboración e impulso de la primera respecto de la segunda. Así las cosas, resulta forzoso que los entes jurisdiccionales adopten una actitud en favor del arbitraje que haga explícita su voluntad de fomentar el acceso a este mecanismo de solución alternativa de conflictos. Adicionalmente, con este criterio, las posturas "pro arbitraje" deben redundar en fórmulas de interpretación que, en caso de duda, sean resueltas favorablemente respecto de esta institución para promover así su autonomía y eficacia. Finalmente, se predica de este sistema que de acuerdo con el "principio de interpretación constitucional conforme" toda norma que consagre el tratamiento del arbitraje no debe 
interferir en su realización efectiva ni imponer límites o talanqueras que impidan su adecuado funcionamiento (Hernández-Bretón, 2007).

Lo anteriormente señalado tiene como razón fundamental promover un amplio sentido de colaboración recíproca entre las autoridades jurisdiccionales y los tribunales de arbitramento, de tal manera que se desestimulen estructuras de jerarquización, claramente incompatibles con las funciones que en este plano cada una de esas instancias tiene atribuidas.

Ahora bien, pese a lo virtuoso e idóneo que en este sentido pueda calificarse el sistema de derecho positivo arbitral vigente en Venezuela, la práctica judicial ha evidenciado ciertas dificultades en su asimilación. Por un lado, se destaca que la Sala Constitucional ha reconocido el carácter jurisdiccional de la misión del árbitro y que, a pesar de ello, la institución del arbitraje forma parte del sistema de justicia pero no del Poder Judicial propiamente dicho. Sin embargo, las posturas de la Sala Constitucional que desarrollan favorablemente la promoción del arbitraje desde la perspectiva del Texto Superior contrastan abiertamente con sus apuestas en materia de control jurisdiccional de las decisiones arbitrales. En efecto, el mencionado tribunal ha incurrido en la tendencia del control constitucional de los laudos, tanto nacionales como internacionales, admitiendo así la posibilidad de impugnarlos a través de mecanismos específicos de protección constitucional como el recurso de amparo, pese a la existencia del recurso de anulación como único mecanismo para supervisar las actuaciones de estos entes encargados de la resolución de disputas (De Jesús, 2006).

\section{DIVERSAS POSTURAS ACERCA DEL PROCESO DE CONSTITUCIONALIZACIÓN DEL ARBITRAJE}

De los ejemplos anteriormente señalados podemos entender que la definición que los textos constitucionales hacen del arbitraje, así como su desarrollo legal y las posturas históricas que la jurisprudencia y la doctrina han adoptado respecto de este, contribuyen en mayor o menor medida a la determinación de sus formas y a su práctica. Así mismo, es claro que el proceso de constitucionalización de esta figura ha contribuido a que los estamentos de control constitucional asuman posturas que tienden a favorecer su autonomía o que, por el contrario, fomenten instrumentos que permiten la existencia de mayores controles e injerencias por parte de las autoridades estatales.

Es así como podemos entender que la calificación del arbitraje como un instrumento de carácter jurisdiccional, con sus variantes, así como las concepciones contractualistas que fundan su percepción desde una perspectiva prevalentemente privada y de alcance particular, son una innegable consecuencia de las formas en las que el ordenamiento jurídico ha optado por configurarlo. En este camino, resulta trascendental, por no decir preeminente, la manera en que el Texto Constitucional lo consagra, cuando así lo hace, aunque hoy en día esto no se puede desligar del activo papel que desempeñan los tribunales constitucionales. 


\section{A. Posturas que favorecen la constitucionalización del arbitraje}

Una corriente importante que alimenta esta tendencia es la proveniente de las mismas esferas constituyentes de los países que optaron por esta fórmula, así como de sus entes legislativos y organismos jurisdiccionales que fundan sus decisiones en esta opción configurativa.

La exposición de motivos de la Constitución de la República Bolivariana de Venezuela (2000), consagró:

Asimismo, siendo que la administración de justicia no es monopolio exclusivo del Estado, aunque solo éste puede ejercer la tutela coactiva de los derechos, es decir, la ejecución forzosa de las sentencias, la Constitución incorpora al sistema de justicia a los ciudadanos que participan en el ejercicio de la función jurisdiccional integrando jurados o cualquier otro mecanismo que la ley prevea.

En este mismo sentido y de forma complementaria, el Tribunal Supremo de Justicia de ese país, en sentencia del 17 de octubre de 2008 se pronunció sobre el particular, así:

Desde una perspectiva histórico estructural del ordenamiento jurídico, la constitucionalización del arbitraje como medio alternativo de solución de conflictos, es el resultado de la tendencia en el foro venezolano de reconocer al arbitraje como un medio idóneo y eficaz para la resolución de conflictos, lo cual se recogió en diversos textos legislativos (aún antes de la entrada en vigor de la vigente Constitución). [Cursivas añadidas].
A lo que añadió:

A juicio de esta Sala, al ampliar la Constitución el sistema de justicia con la inclusión de modos alternos a la resolución de conflictos -entre los que se encuentra el arbitraje- al de la función jurisdiccional ordinaria que ejerce el Poder Judicial, se replanteó el arquetipo del sistema de justicia, lo cual si bien implica un desahogo de la justicia ordinaria, comporta que el arbitraje no pueda ser considerado como una institución ajena al logro de una tutela jurisdiccional verdaderamente eficaz $y$, por lo tanto, excluye la posibilidad que el arbitraje y demás medios alternativos de resolución de conflictos sean calificados como instituciones excepcionales a la jurisdicción ejercida por el Poder Judicial (TSJ, sentencia del 17 de octubre de 2008, L. Morales). [Cursivas añadidas].

Por su parte, el debate que se generó en la Comisión de Estudio de las Bases de la Reforma Constitucional peruana se centró más en la fórmula de consagración que en la conveniencia o inconveniencia de incorporar el arbitraje al Texto Constitucional. En tal sentido, la Comisión se pronunció en los siguientes términos: "Se debe eliminar la referencia a una jurisdicción arbitral ya que técnicamente es inadecuada. Ello no descarta la conveniencia de un reconocimiento constitucional expreso de los diferentes medios alternativos de resolución de conflictos: arbitraje, negociación y conciliación" (Comisión de Estudio de las Bases de la Reforma Constitucional del Perú, 2001). ${ }^{8}$ [Cursivas añadidas].

8 No obstante lo aquí expresado, el resultado último del proceso constituyente peruano optó por la constitucionalización y la "jurisdiccionalización" del arbitraje, al disponer, en el artículo 139, inciso 1, ubicado en el Capítulo VIII, Poder Judicial, lo siguiente: "Artículo 139.- Son principios y derechos de la función jurisdiccional: La unidad y exclusividad 
Como es evidente, este debate se trasladó al escenario doctrinal ya que el Texto Constitucional finalmente reconoció el arbitraje como una jurisdicción. Sin embargo, un importante sector calificó esta fórmula como un error "sistémico" ya que el arbitraje como medio alternativo de solución de controversias nada tiene que ver con la justicia ordinaria. En contraposición, autores como Jaime David Abanto Torres (2006) consideran positiva la inclusión de un artículo sobre medios alternativos de resolución de conflictos en el Texto Constitucional, pero ubicado en el capítulo de los derechos de la persona. En efecto, sostiene el mencionado autor, la libertad es un derecho fundamental que se puede materializar en la voluntad libre que tienen las personas de solucionar sus conflictos y que tiene una estrecha vinculación con su dignidad. El acceso al Poder Judicial debería ser la última alternativa. Y continúa: el llamado "interés para obrar" tiene lugar cuando la persona ha agotado todos los medios para satisfacer su pretensión material y no tiene otra alternativa que recurrir al órgano jurisdiccional.

Otro sector de la doctrina peruana considera que si bien la "hiperconstitucionalización" del arbitraje puede traer más consecuencias negativas que positivas, la importancia del reconocimiento constitucional de la institución en el país suramericano ha permitido que el Tribunal Constitucional blinde al arbitraje de interferencias judiciales y de otro orden, como sucedió en

de la función jurisdiccional. No existe ni puede establecerse jurisdicción alguna independiente, con excepción de la militar y la arbitral. No hay proceso judicial por comisión o delegación" (Comisión de Estudio de las Bases de la Reforma Constitucional del Perú, 2001). las sentencias dictadas en los casos Cantuarias Salaverry y Algamarcas (Santistevan, 2006).

\section{B. Posturas que desincentivan la constitucionalización del arbitraje}

En primer lugar, cabe cuestionarse qué tan significativo es que el arbitraje esté reconocido constitucionalmente y qué tanto aporta este proceso para el desarrollo de este método de solución de controversias en el sistema jurídico de cada país. Desde una perspectiva objetiva, dicho aporte no es significativo y es prueba de ello que ningún país europeo tiene semejante precepto constitucional sobre el arbitraje y que esta condición no ha impedido un desarrollo vigoroso de la institución. Tampoco lo tienen los países de Norteamérica, incluyendo los de tradición anglosajona, ni los del Asia y África. En estos lugares del mundo, el arbitraje debe su funcionamiento al principio de libertad contractual y a entornos legales que favorecen su desarrollo (Santistevan, 2010).

En efecto, la no consagración de la figura en el Texto Constitucional no parece presentar desventaja alguna a la hora de su inclusión y efectivo desarrollo en el plano legal. ${ }^{9}$ Tal es el caso, entre muchos otros, del ordenamiento español, en el que la Ley 60/2003, que regula lo relativo al arbitraje nacional e internacional, no encuentra referente o soporte alguno en la normativa superior. Sobre el particular, José Fernando Merino Merchán (2009) critica con severidad

\footnotetext{
9 Las discusiones sobre la constitucionalidad del arbitraje han tenido lugar tanto en países en donde está reconocido en la Constitución como en aquellos en los que dicho mecanismo no opera (Fernández, 2008).
} 
aquellas posiciones que reniegan del arbitraje y claman por su inconstitucionalidad por el mero hecho de no existir mención de este en la Carta Política. En palabras del renombrado tratadista, la prescripción relativa a la exclusiva potestad de los jueces y tribunales para juzgar y ejecutar lo juzgado se refiere a los diversos tipos de procesos judiciales, y el arbitraje no tiene un origen procesal en sí mismo sino que se funda en la inderogable autonomía de la voluntad de los ciudadanos como sujetos libres, lo que no implica su renuncia al derecho fundamental de acceso a la jurisdicción.

En últimas, es posible entender que esta problemática no es ajena al debate sobre la constitucionalización del derecho privado al que hemos hecho referencia en el presente escrito. Para algunos autores, el proceso de constitucionalización del arbitraje constituye solo una parte de un fenómeno más amplio de constitucionalización de las diferentes ramas de los derechos nacionales, que ha venido entrabando la estabilidad de los sistemas de derecho civil por varias décadas. En criterio de este sector de la doctrina, el problema de mayor envergadura consiste en que se ha venido reemplazando la legislación, como fuente primaria de derecho, por jurisprudencia constitucional, la cual es ampliamente conocida por su contenido político y sociológico, más que por su sustrato técnico-jurídico. En este orden de ideas, las controversias relativas al arbitraje no son resueltas por los estatutos legales sino por disposiciones de rango constitucional o, lo que es peor, por principios constitucionales definidos en las cartas políticas y en la jurisprudencia constitucional (De Jesús, 2007).

\section{CONCLUSIÓN}

El proceso de constitucionalización del arbitraje en Colombia se remonta a épocas anteriores a la Constitución de 1991, cuando la Corte Suprema de Justicia, en ausencia de un Texto Superior consagratorio, definió las características esenciales de la figura y determinó los parámetros bajo los cuales habría de definirse en el nuevo cuerpo normativo fundamental. Sin embargo, el mayor desarrollo jurisprudencial tuvo lugar tras la incorporación del arbitraje en la Carta de 1991, cuando la Corte Constitucional, en consonancia con la fórmula adoptada por el constituyente, definió directrices que encasillaron al arbitraje como mecanismo jurisdiccional y con las características de un proceso en que los árbitros se comportan como verdaderas autoridades judiciales sin más límites que los materialmente definidos por la arbitrabilidad.

Esta caracterización del arbitraje ha tenido importantes consecuencias a la hora de determinar su autonomía, ya que la búsqueda de soluciones a problemáticas planteadas en su seno apunta más hacia el plano del Texto Constitucional, del derecho procesal y de las normativas que rigen la actividad judicial que a las disposiciones especiales sobre la materia. De igual manera, la procedencia de acciones constitucionales de amparo o tutela judicial para todas las instancias del trámite, aún sin haber activado mecanismos inherentes al mismo -recurso de anulación- ha generado espacios de incertidumbre cuando se trata de buscar soluciones definitivas, especializadas y oportunas. 
Ahora bien, es claro que la modalidad de consagrar el arbitraje como elemento integrante del Poder Judicial no es la única fórmula para su incorporación en la Normativa Superior. La apuesta por reconocer el arbitraje como un derecho fundamental, de manera directa o indirecta, debería plantear al juez constitucional y a las autoridades estatales la necesidad de promover una cultura pro arbitraje en que las manifestaciones de los poderes públicos se dirijan a favorecer y facilitar esta alternativa como una manifestación esencial de las libertades individuales.

No obstante, resulta necesario preguntarse: ¿en qué radica la importancia del reconocimiento constitucional y cuáles son las diferencias prácticas entre los sistemas que constitucionalizan el arbitraje y los que no? Sobre el particular, resulta apresurado proponer corolarios ya que no es posible concluir que el reconocimiento constitucional, per se, incentive o desincentive el arbitraje. Ahora bien, en este punto no es posible desconocer la preocupación esgrimida por algunos autores nacionales, entre ellos Eduardo Zuleta Jaramillo (2001), en cuanto a las consecuencias paralizantes que genera que la Constitución colombiana encuadre la figura en el marco de la jurisdicción oficial. Tampoco se puede desconocer que en casos como el de Costa Rica y El Salvador, en los que el Texto Superior atribuye al arbitraje la condición de derecho fundamental, ello no necesariamente deriva en un adecuado desarrollo de la práctica arbitral.

Finalmente, se rescata el planteamiento de que la constitucionalización del arbitraje solo puede ser visto como un fenómeno positivo, en la medida en que las normas y los principios constitucionales sobre el particular sean aplicados como meras guías de carácter político y no como normas supremas que puedan entrar en conflicto con otras de carácter infraconstitucional, como las normas especiales de arbitraje, y supraconstitucional, como los tratados internacionales sobre la materia (De Jesús, 2007).

\section{Referencias}

Abanto Torres, J. D. (2006). El arbitraje en las sentencias del Tribunal Constitucional y la procedencia del amparo contra laudos arbitrales. Revista Peruana de Arbitraje, (3), 137194.

Asamblea Nacional Constituyente. Comisión Cuarta. (1991a). Gaceta Constitucional n. ${ }^{\circ}$ 81; mayo 24 de 1991.

Asamblea Nacional Constituyente. Comisión Cuarta. (1991b). Gaceta Constitucional n. ${ }^{\circ}$ 119; agosto 16 de 1991.

Cámara de Comercio de Bogotá. (2008). La constitucionalización del arbitraje. En Cámara de Comercio de Bogotá. Centro de Arbitraje y Conciliación, Notas de arbitraje (págs. 137172). Bogotá: Cámara de Comercio de Bogotá: Uniempresarial.

Centro de Investigaciones Jurídicas. Academia de Ciencias Políticas y Sociales. (Agosto 5 de 2013). Arbitraje en Venezuela y derecho comparado. Obtenido de cij: http://cij.org.ve/ 
site/arbitraje-en-venezuela-y-derecho-comparado/

Comisión de Estudio de las Bases de la Reforma Constitucional del Perú. (Julio de 2001). Lineamientos para una reforma constitucional. Obtenido de congreso: http://www.congreso. gob.pe/comisiones/2002/debate_constitucional/bases.htm

Conejero Roos, C. (2009). El arbitraje comercial en Iberoamérica: un panorama general. En C. Conejero Roos, et al., El arbitraje comercial internacional en Iberoamérica. Bogotá: Legis Editores S. A.

Congreso de la República de Colombia. (12 de julio de 2012). Ley 1563 de 2012. Por medio de la cual se expide el Estatuto de Arbitraje Nacional e Internacional y se dictan otras disposiciones.

Constitución de la República Bolivariana de Venezuela.

Constitución Política de El Salvador.

Constitución Política de Honduras.

Constitución Política de la República de Colombia. 1991.

Constitución Política de la República de Costa Rica. 7 de noviembre de 1949.

Constitución Política de Panamá.

Constitución Política de Paraguay.
Constitución Política del Perú.

Corte Constitucional de Colombia. Sentencia C-592 de 1992 (M. P.: Fabio Morón Díaz; diciembre 7 de 1992).

Corte Constitucional de Colombia. Sentencia C-426 de 1994 (M. P.: José Gregorio Hernández; septiembre 29 de 1994).

Corte Constitucional de Colombia. Sentencia C-294 de 1995 (M. P.: Jorge Arango Mejía; julio 6 de 1995).

Corte Constitucional de Colombia. Sentencia C-431 de 1995 (M. P.: Hernando Herrera Vergara; septiembre 28 de 1995).

Corte Constitucional de Colombia. Sentencia C-451 de 1995 (M. P.: Eduardo Cifuentes Muñoz; octubre 4 de 1995).

Corte Constitucional de Colombia. Sentencia C-242 de 1997 (M. P.: Hernando Herrera Vergara; mayo 20 de 1997).

Corte Constitucional de Colombia. Sentencia C-330 de 2000 (M. P.: Carlos Gaviria Díaz; marzo 22 de 2000).

Corte Constitucional de Colombia. Sentencia C-1436 de 2000 (M. P.: Alfredo Beltrán Sierra; octubre 25 de 2000).

Corte Constitucional de Colombia. Sentencia C-098 de 2001 (M. P.: Martha Victoria Sáchica; enero 31 de 2001). 
Corte Constitucional de Colombia. Sentencia C-1038 de 2002 (M. P.: Eduardo Montealegre Lynett; noviembre 28 de 2002).

Corte Suprema de Justicia de Colombia. Sala Plena (M. P.: Luis Sarmiento Buitrago; mayo 29 de 1969).

Corte Suprema de Justicia de Colombia. Sala Plena. Expediente 2227 (M. P.: Pedro Escobar Trujillo; marzo 21 de 1991).

Corte Suprema de Justicia de Costa Rica. Sala Primera. Res: 000594-F-00; agosto 18 de 2000. Obtenido de: http://sitios.poder-judicial.go.cr/sala1/Textos\%20fallos\%20relevantes/Achivos\%20pdf/594-F-00.pdf

Corte Suprema de Justicia de El Salvador. Sala de lo Constitucional. Sentencia 11-2010: 30 de noviembre de 2011. Diario Oficial n. 234 , Tomo 393 de fecha 14/12/2011.

Cremades, B. y Cairns, D. (2002). El arbitraje en la encrucijada entre la globalización y sus detractores. Revista de la Corte Española de Arbitraje, (17), 15-61.

De Jesús O., A. (2006). La Sala Constitucional y el arbitraje comercial. Hacia un régimen racional del control judicial del laudo arbitral en el derecho venezolano. Obtenido de Revista Peruana de Arbitraje: http://www.peruarbitraje.org/pdf/revista/REVISTA_PERUANA_ DE_ARBITRAJE_RPA_3_2006.pdf

De Jesús O., A. (2007). The impact of constitutional law on international commercial arbi- tration in Venezuela. Journal of International Arbitration, XXIV(1), 69-80.

El Salvador. Decreto Legislativo n. ${ }^{\circ} 141$ (octubre 1 de 2009). Reformas a la Ley de mediación, conciliación y arbitraje.

Exposición de motivos de la Constitución de la República Bolivariana de Venezuela. Gaceta Oficial n. ${ }^{\circ}$ 5.453. Extraordinario de fecha 24 de marzo del año 2000.

Fernández Rozas, J. C. (2008). Tratado del arbitraje comercial en América Latina. Madrid: lustel.

Fundación Estudios de Derecho Administrativo. (1999). Compilación de las Constituciones Políticas. Caracas: FUNEDA.

Fundación Salvadoreña para el Desarrollo Económico y Social. (Marzo de 2005). Aspectos prácticos del arbitraje en El Salvador. Recuperado el 6 de octubre de 2014, de Boletín de Estudios Legales: FUSADES: http://biblioteca.utec.edu.sv/siab/virtual/estudios_legales_fusades/fel_51.pdf

García Mirón, R. (Marzo 22 de 2012). Sobre la penosa sentencia 11-2010. Apelación en arbitrajes de derecho en El Salvador. Obtenido de abogae: http://www. abogae.com.ar/sobre-la-penosa-sentencia11-2010-apelaci\%C3\%B3n-en-arbitrajes-dederecho-en-el-salvador

Gómez Rodas, C. y Gómez Fonseca, F. (2010). Costa Rica. En A. Zapata de Arbeláez, S. Ba- 
rona Vilar y C. Esplugues Mota, El arbitraje interno e internacional en Latinoamérica. Regulación, presente y tendencias del futuro (págs. 309-333). Bogotá: Universidad Externado de Colombia.

González de Cossío, F. (2005). Chauvinism rejected: Mexican Supreme Court upholds the constitutionality of the Mexican Arbitration Statute. Journal of International Arbitration, XXII(2), 163-166.

Hernández-Bretón, E. (2007). Significado constitucional del arbitraje en Venezuela. En C. Larroumet, Ríos Labbé, S. y Association Andrés Bello des Juristes Franco-Latino-Américains, Constitucionalización del derecho privado. Actas del Tercer Congreso Internacional de la Association Andrés Bello Des Juristes FrancoLatino-Américains. Bogotá: Universidad Externado de Colombia.

Ibáñez Najar, J. E. (2009). La acción de tutela contra laudos arbitrales. Bogotá: Pontificia Universidad Javeriana/Depalma/Ibáñez.

Jiménez Figueres, D. (s.f.). Una visión siempre optimista: la nueva Ley de Arbitraje Comercial Internacional de Costa Rica. Recuperado el 9 de abril de 2014, de Latin Arbitration Law: http://www.latinarbitrationlaw.com/una-visin-siempre-optimista-la-nueva-ley-de-arbitrajecomercial-internacional-de-costa-rica/

Lobo Lara, F. D. y Lobo Flores, F. D. (2010). Honduras. En A. Zapata de Arbeláez, S. Barona Vilar y C. Esplugues Mota, El arbitraje interno e internacional en Latinoamérica. Regulación, presente y tendencias del futuro (págs. 503-530). Bogotá: Universidad Externado de Colombia.

Merino Merchán, J. F. (2009). Curso de Derecho Arbitral. Valencia: Tirant Lo Blanch.

Mourre, A. (2007). Los méritos de la "constitucionalización" del procedimiento civil y del derecho del arbitraje. En C. Larroumet, Ríos Labbé, S. y Association Andrés Bello des Juristes Franco-Latino-Américains et al., Constitucionalización del derecho privado. Actas del Tercer Congreso Internacional de la Association Andrés Bello Des Juristes Franco-Latino-Américains. Bogotá: Universidad Externado de Colombia.

Osorio, M. (Enero-Junio, 2012). Arbitraje: un caso en contra de la constitucionalización de los mecanismos alternativos de solución de conflictos. Obtenido de http://derechoprivado.uniandes.edu.co

Santistevan de Noriega, J. (2006). Arbitraje y jurisdicción desde la perspectiva del Tribunal Constitucional del Perú. Revista Peruana de Arbitraje, (2), 15-66.

Santistevan de Noriega, J. (2010). La habilitación constitucional para el arbitraje con el Estado y su desarrollo en el Perú. Revista de Arbitraje Comercial y de Inversiones, III(1), 43-83.

Silva Romero, E. (Julio-Septiembre de 2011). La nouvelle loi costaricienne sur l'arbitrage com- 
mercial international du 25 mai 2011. Revue de I'Arbitrage, (3), 843.

Tribunal Supremo de Justicia de Venezuela. Sala Constitucional. Expediente n. ${ }^{\circ}$ 08-0763 (M. P.: Luisa Estella Morales Lamuño; octubre 17 de 2008).

Victoria-Andreu, F. (2007). Virtudes de la constitucionalización del procedimiento civil y del arbitraje. En C. Larroumet, Ríos Labbé, S. y
Association Andrés Bello des Juristes FrancoLatino-Américains, Constitucionalización del derecho privado. Actas del Tercer Congreso Internacional de la Association Andrés Bello Des Juristes Franco-Latino-Américains. Bogotá: Universidad Externado de Colombia.

Zuleta Jaramillo, E. (2001). Special Constitutional Action to Preserve International Arbitration. Journal of International Arbitration, XVIII(4), 475-480. 